\title{
Climatological variability of surface particulate organic carbon (POC) and physical processes based on ocean color data in the Gulf of Mexico
}

\author{
Young Baek Son ${ }^{\dagger}$ and Wilford D. Gardner** \\ * Korea Ocean Satellite Center, KORDI, 1270 Sadong, Ansan 426-744, Korea \\ ** Department of Oceanography, Texas A\&M University, College Station, Texas, USA, 77843-3146
}

\begin{abstract}
The purpose of this study is to investigate climatological variations from the temporal and spatial surface particulate organic carbon (POC) estimates based on SeaWiFS spectral radiance, and to determine the physical mechanisms that affect the distribution of POC in the Gulf of Mexico. 7 -year monthly mean values of surface POC concentration (Sept. 1997 - Dec. 2004) were estimated from Maximum Normalized Difference Carbon Index (MNDCl) algorithm using SeaWiFS data. Synchronous 7year monthly mean values of remote sensing data (sea surface temperature (SST), sea surface wind (SSW), sea surface height anomaly (SSHA), precipitation rate (PR)) and recorded river discharge data were used to determine physical forcing factors. The spatial pattem of $\mathrm{POC}$ was related to one or more factors such as river runoff, wind-derived current, and stratification of the water column, the energetic Loop Current/Eddies, and buoyancy forcing.

The observed seasonal change in the POC plume's response to wind speed in the westem delta region resulted from seasonal changes in the upper ocean stratification. During late spring and summer, the lowdensity river water is heated rapidly at the surface by incoming solar radiation. This lowers the density of the fresh-water plume and increases the near-surface stratification of the water column. In the absence of significant wind forcing, the plume undergoes buoyant spreading and the sediment is maintained the surface by the shallow pycnocline. However, when the wind speed increases substantially, wind-wave action increases vertical motion, reducing stratification, and the sediment were mixed downward rather than spreading laterally. Maximum particle concentrations over the outer shelf and the upper slope during lower nunoff seasons were related to the Loop Current/eddies and buoyancy forcing.

Inter-annual differences of POC concentration were related to ENSO cycles. During the El Niño events (1997-1998 and 2002-2004), the higher POC concentrations existed and were related to high runoffs in the eastem Gulf of Mexico, but the opposite conditions in the western Gulf of Mexico. During La Niña conditions (1999-2001), low POC concentration was related to nomal or low river discharge, and low PM/nutrient waters in the eastem Gulf of Mexico, but the opposite conditions in the western Gulf of Mexico.
\end{abstract}

Key Words : Particulate organic carbon (POC), SeaWiFS, Gulf of Mexico, Maximum Normalized Difference Carbon Index (MNDCI), EOF.

Received May 16,2011; Revised June 7, 2011; Accepted June 8, 2011.

${ }^{\dagger}$ Corresponding Author: Young Baek Son (sonyb@kordi.re.kr) 


\section{Introduction}

One of the important biogeochemical cycles is the carbon cycle. Many. studies have been made to determine ocean carbon dynamics using in situ observations and remotely sensed data. The Joint Global Ocean Flux Study(JGOFS), the World Ocean Circulation Experiment(WOCE), South Atlantic Ventilation Experiment(SAVE), North Atlantic Bloom Experiment(NABE), and Bermuda Atlantic Time Series Station(BATS) have provided some understanding of the production and export of carbon from the surface ocean to the deep sea floor(Gardner et al., 1993, 2000, and 2006; Chung et al., 1998; Mishonov et al., 2000; Berelson, 2001). It is difficult to estimate the amount and distribution of ocean carbon at basin and global scales from ship-based surveys, because it is a very labor and time demanding procedure.

Recently, new ocean color studies have presented biological, ecological and oceanographic information from various water types. They could determine particulate organic carbon(POC) variations with much better temporal and spatial coverage than the very limited data offered by ship observations (Stramski et al., 1999; Mishonov et al., 2003; Gardner et al., 2006; Son et al., 2009a and 2009b). Time series data of other physical oceanic parameters could provide ancillary data to POC concentrations to determine climatological variations and physical forcing functions. In order to determine the physical processes, ocean observations were carried out by various satellite sensors.

To identify climatologically important time scales and oceanographic processes, routine archives have been used to study time-series patterns of interesting oceanographic parameters. Empirical orthogonal function(EOF) analysis has become standard statistical methods in the meteorology and
oceanography(Preisendorfer, 1988; Emery and Thomson, 1997; Kantha and Clayson, 2000). This has become a particularly useful tool in studying large quantities of multi-variable data(Thomas et al., 2003). The eigenfunctions allow us to represent spatial and temporal variability as a number of empirical modes. Because most of the variance in the data can be captured by a small number of modes, their decomposition may be useful for interpreting the variability in various fields. Most EOF studies using ocean color provide the temporal variations with seasonal / inter - annual time scales and the spatial variations to one or more oceanographic processes. EOF analysis also explains physical dynamics based on the signal strength of EOF parameters tested(Kantha and Clayson, 2000; Thomas et al., 2003). The dominant signals identify temporal and spatial indices of change in the oceanic environment.

The Gulf of Mexico is a semi-enclosed basin with passages at the Yucatan Channel and the Florida Straits(Fig. 1). The Gulf of Mexico has a broad continental shelf and narrow continental slope, and its maximum water depth is about $3,600 \mathrm{~m}$. This area consists of a broad continental shelf and a narrow continental slope and rise. Several river systems on the surrounding land provide a large mass of fresh water to the shelf along with suspended sediments, organic and inorganic matter, and pollutants. The largest riverine source is the Mississippi-Atchafalaya System(Walker et al., 1994), which drains approximately $40 \%$ of the continental United States. Due to the input of organic and inorganic materials, the Mississippi River plume has been identified as a potentially important factor in the high level of primary production found in the northern Gulf of Mexico, and strongly influences seasonal and interannual circulation patterns(Rabalais et al., 1996; Walker, 1996; Son et al., 2009b; Son and Gardner, 2010). The continental shelf in the northwestern Gulf 


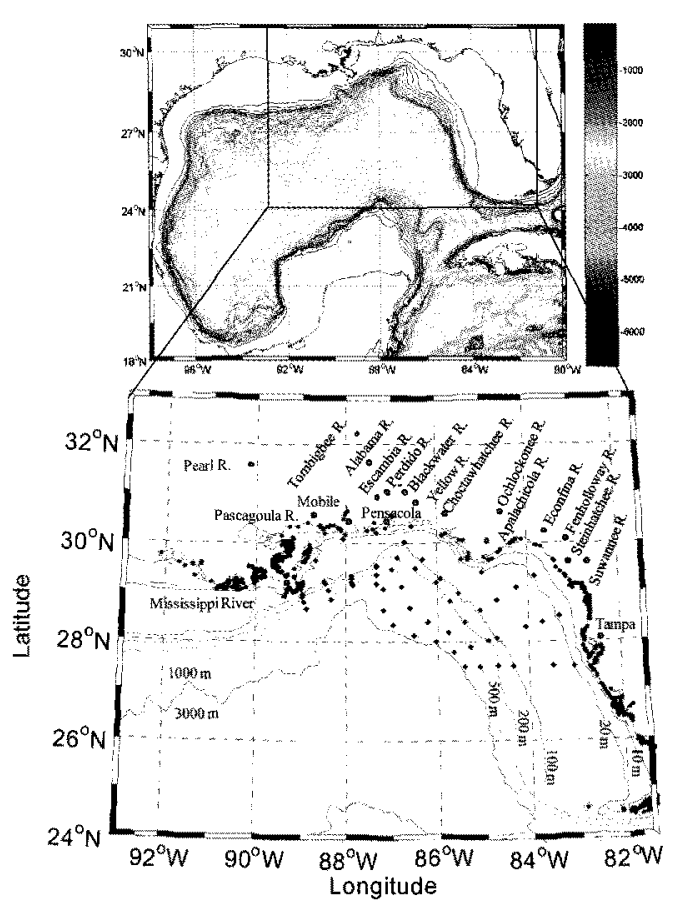

Fig. 1. Bathymetry and sampling stations in the Northeastern Gulf of Mexico(NEGOM).

of Mexico has a broad, nearly uniform bathymetry, and is 200 kilometer in width between Louisiana $\left(92^{\circ}\right.$ W) and the Texas-Louisiana border $\left(94^{\circ} \mathrm{W}\right)$. The bathymetry generally remains parallel to the shoreline two hundred meters from shore to the shelf. The Florida platform is a broad and gently sloping region formed by a sequence of deep-water carbonates. The general circulation along the Florida coast is complex because of the combination of tides, winds, and river buoyancy forcing. In the mesoscale circulation system, the Loop Current(LC) or Loop Current Eddies(LCE) significantly affects the circulation of the Gulf of Mexico(Hofmann and Worley, 1986; Hamilton et al., 1999 and 2002; Sturges and Leben, 2000; Frolov et al., 2004). As the precursor of the Gulf Stream, the Loop Current enters the Gulf through the Yucatan Channel and flows in a generally clockwise direction before leaving through the Florida Straits. The loop current generates warm core eddies that move to the western Gulf of Mexico and often spin up anti-cyclonic cold core eddies. The LC and LCE were located at the south and southwest of the Mississippi River Delta and sometimes was elongated and extended in an east-west orientation. The frontal area between these eddies can cause an entrainment of coastal waters and transport off the shelf(Brooks and Legeckis, 1982). Low POC concentration matched well with the Loop Current and warm-core eddy, and high POC plume located the edge of Loop Current and between eddies(Son and Gardner, 2010).

Wide-rang surface rivers discharge a seasonally varying mass of particulate matter onto the shelf, after which its distribution is controlled by local and mesoscale circulation. The fate of surface particulate material released to the northern Gulf of Mexico is controlled by one or a combination of factors(Gilbes et al., 1996). In this study we will investigate annual and inter-annual variations of particulate matter, especially particulate organic carbon( $\mathrm{POC}$ ), and determine the physical forcing factors that significantly affect the distribution of particulate materials with matching satellite data. Satellite remote sensing data were used to detect changes in the particle distributions as affected by river discharge, local wind stresses, the Loop Current, and Loop Current eddies. The influence of each factor is examined.

\section{Data and Methods}

\section{1) River Discharge Data for the northern Gulf of Mexico}

Historical river discharge rates were obtained for the larger rivers between the Mississippi River(Louisiana) and the Suwannee River(central Florida) from USGS(http://waterdata.usgs.gov/nwis/ 
sw) and U.S. Army Corps of Engineers(http://www.mvn. usace.army.mil/eng/edhd/Wcontrol/miss.htm). Longterm means of monthly discharge from September 1997 to December 2004 were collected. River discharge regions were classified into six areas, and the values were summed with each river discharge rate: 1) Mississippi River; 2) Mississippi area including the Pearl and Pascagoula River; 3) Alabama Area including Tombigbee and Alabama River; 4) West Florida Area including Escambia, Perdido, Blackwater, and Yellow River; 5) Middle Florida Area including Choctawhatchee, Ochlockonee, and Apalachicola River; 6) East Florida Area including Econfina, Fenholloway, Steinhatchee, and Suwannee River(Fig. 1).

\section{2) Remotely Sensed Data}

The daily Sea-viewing Wide Field-of-view Sensor(SeaWiFS) satellite images(Level 1A) covering the Gulf of Mexico were obtained from the NASA Ocean Biology Processing Group(http:// oceancolor.gsfc.nasa.gov/). L1A data recorded at the top of the atmosphere(TOA) were atmospherically corrected and were processed to Level 2 using the SeaWiFS Data Analysis System(SeaDAS)(McClain et al., 2004) software. Normalized water-leaving radiance data were used to estimate $\mathrm{POC}$ concentration using MNDCI(Maximum Normalized Difference Carbon Index) algorithm(Son et al., 2009b) and then calculate climatological monthly mean values(September 1997 to December 2000).

The daily sea surface temperature(SST) composite images(September 1997 to December 2000) from the NOAA Advanced Very High Resolution Radiometer (AVHRR) were obtained from the Physical Oceanography Distributed Active Archive Center (PO.DAAC) at Jet Propulsion Laboratory(JPL), California Institute of Technology(http://podaac. jpl.nasa.gov/index.html). These level 3 data(Version
5) consisted of the standard map projection, and they were remapped to the same projection for POC data.

Along-track sea surface height anomaly(SSHA) data were obtained from TOPEX/POSEIDON altimeters at PO.DAAC(http://podaac.jpl.nasa. gov/index.html) and calculated along grid values. A standard correction was applied to the altimeter data set, and they were reconfigured to a regular grid of 9 $\mathrm{km}$ resolution per pixel. Partial compensation for the loss of the sea height associated with the mean field height is removed. With a repeated mission every 10 days, monthly mean values of SSHA data were calculated for the same region(September 1997 to December 2000). Temporal development of LC and LCE features was examined through the evolution of SSHA over the Gulf of Mexico.

The daily sea surface wind(SSW) and precipitation Rate(PR) data, achieved from QuickScat and the Special sensor Microwave/Image(SSM/I), were download from the Remote Sensing System in Santa Rosa, California(http://www.remss.com) and remapped to the same projection and calculated the monthly mean values(September 1997 to December 2000).

\section{3) Empirical Orthogonal Function(EOF) Analysis}

In order to detect temporal and spatial patterns of a large ocean color data set in the Gulf of Mexico, EOF analysis(Son, 2006) was calculated with a monthly time-series data of POC estimates, SST, SSHA, SSW, and PR data during 88 months(September 1997 to December 2004). Paden et al.(1991) suggested that removing each mean value from the temporal and spatial dimension of the data matrix before EOF analysis provided more detailed information from EOF analysis. Since the removal of the temporal and spatial mean values revealed patterns that varied strongly in time and space, i.e. the 
variations from the mean. From the data matrix, we first removed the record mean from each column (temporal dimension) and row(spatial dimension). Second, we normalized the demeaned time series by dividing each column by its standard deviation. This approach ensured that no data points in the time series were dominated by the variance, but all data were given an equal opportunity to contribute in the analysis. The resulting demeaned and normalized series were termed standardized series.

Each EOF unit was interpreted considering amplitude and spatial patterns as a unit of information. A given EOF pattern described a spatial pattern of residual variance, which was modulated by its corresponding time-varying amplitude. This provided spatial and temporal patterns and elucidated the relationship between POC concentrations and physical processes in the Gulf of Mexico.

Each EOF pattern and time series was useful for describing POC distributions and temporal variations. It was not enough to determine the relationship between POC and physical processes using single value EOF analysis. For understanding the covariability of two fields at a time, the combined empirical orthogonal function(CEOF) analysis was tested to determine relationships between $\mathrm{POC}$ and satellite data(SST, SSHA, SSW, and PR) after removing the temporal mean value(Son, 2006). The simplest variation to EOF analysis is CEOF, developed to investigate the covariability(or joint variability) of two or more fields at a time. The correlation coefficient between the two PCs of modes provides a measure of how strongly fields are related to one another through modes(Frankignoul et al., 1996; Son, 2006).

\section{Results}

\section{1) Climatological Variations of POC}

The climatological monthly mean(September 1997-December 2004) of surface POC estimates based on MNDCI(Maximum Normalized Difference Carbon Index) algorithm(Son et al., 2009b) were used to create distribution maps for the Gulf of Mexico(Fig. 2). The highest POC values were consistently on the inner shelf, diminishing offshore. Higher POC concentrations were spatially observed during the summer and lower values occurred during the fall.

During the fall(September-November), surface POC concentrations of over $100 \mathrm{mg} / \mathrm{m}^{3}$ were confined to the inner shelf along the Gulf coast, but slightly extended over the narrow outer shelf near the Mississippi Delta. Over the rest of the outer shelf and the upper slope, concentrations dropped off rapidly, to $<100 \mathrm{mg} / \mathrm{m}^{3}$ at the seaward of the study area(Fig. 2). During the spring(March-May), surface POC concentrations over $100 \mathrm{mg} / \mathrm{m}^{3}$ were generally confined to the inner shelf as during the previous fall season. Most of the higher concentrations of POC occurred between Mobile Bay and the Mississippi Delta, the area into which higher river inputs of the Mississippi, Pearl, and Tombigbee(Alabama) Rivers were discharged. However, high POC concentrations extended out onto the upper slope east of the Mississippi Delta. The easternmost end of the study area, near Tampa Bay, exhibited lower concentrations. During the summer(June-August), elevated surface POC waters $\left(>300 \mathrm{mg} / \mathrm{m}^{3}\right)$ stretched from the shelf east of the Mississippi River over the upper slope in a northwest-southeast direction(Fig. 2). The lowest surface concentrations encountered along the edge of the upper slope in the west and eastern inner shelf(Son, 2006; Son and Gardner, 2010). 

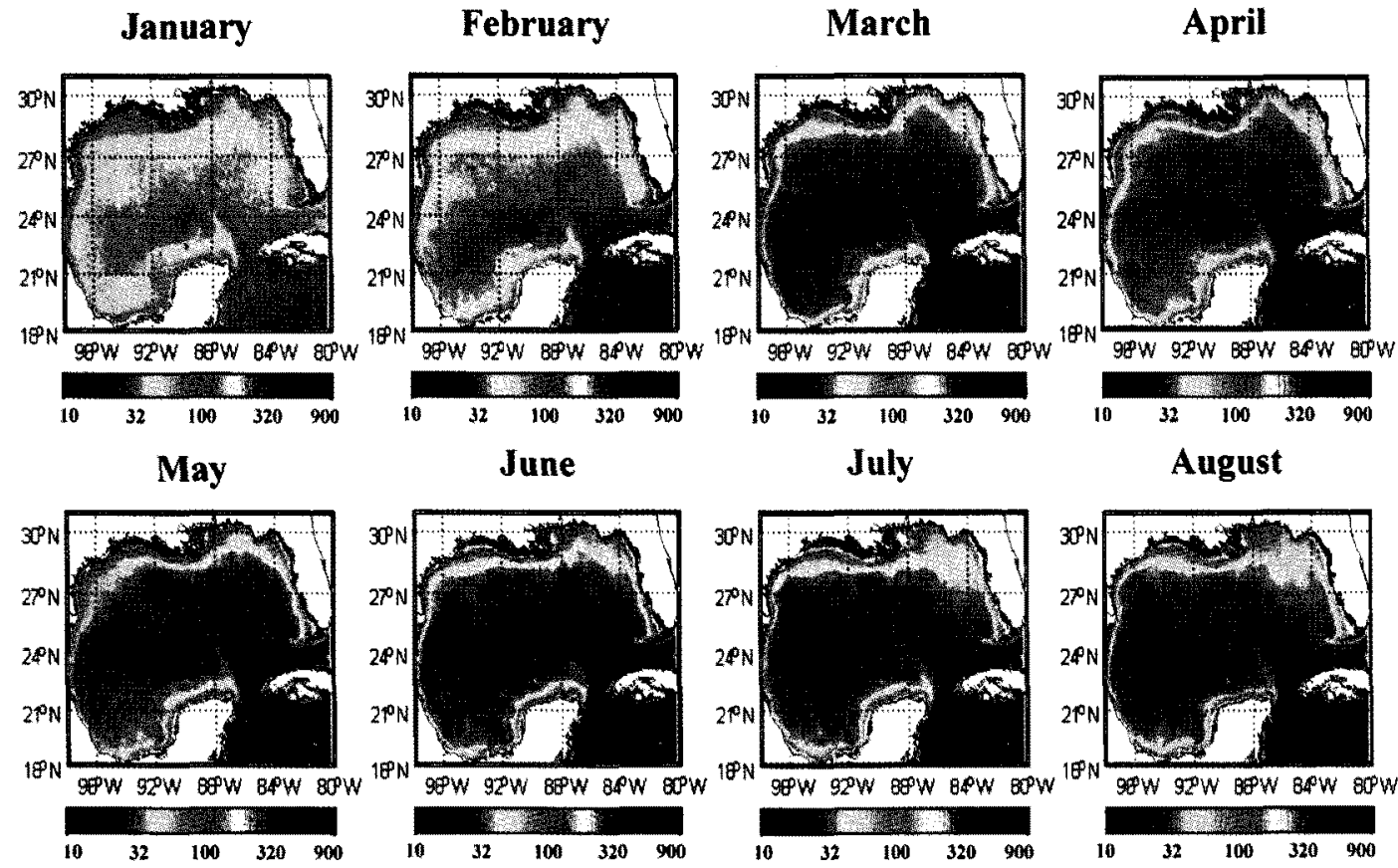

September
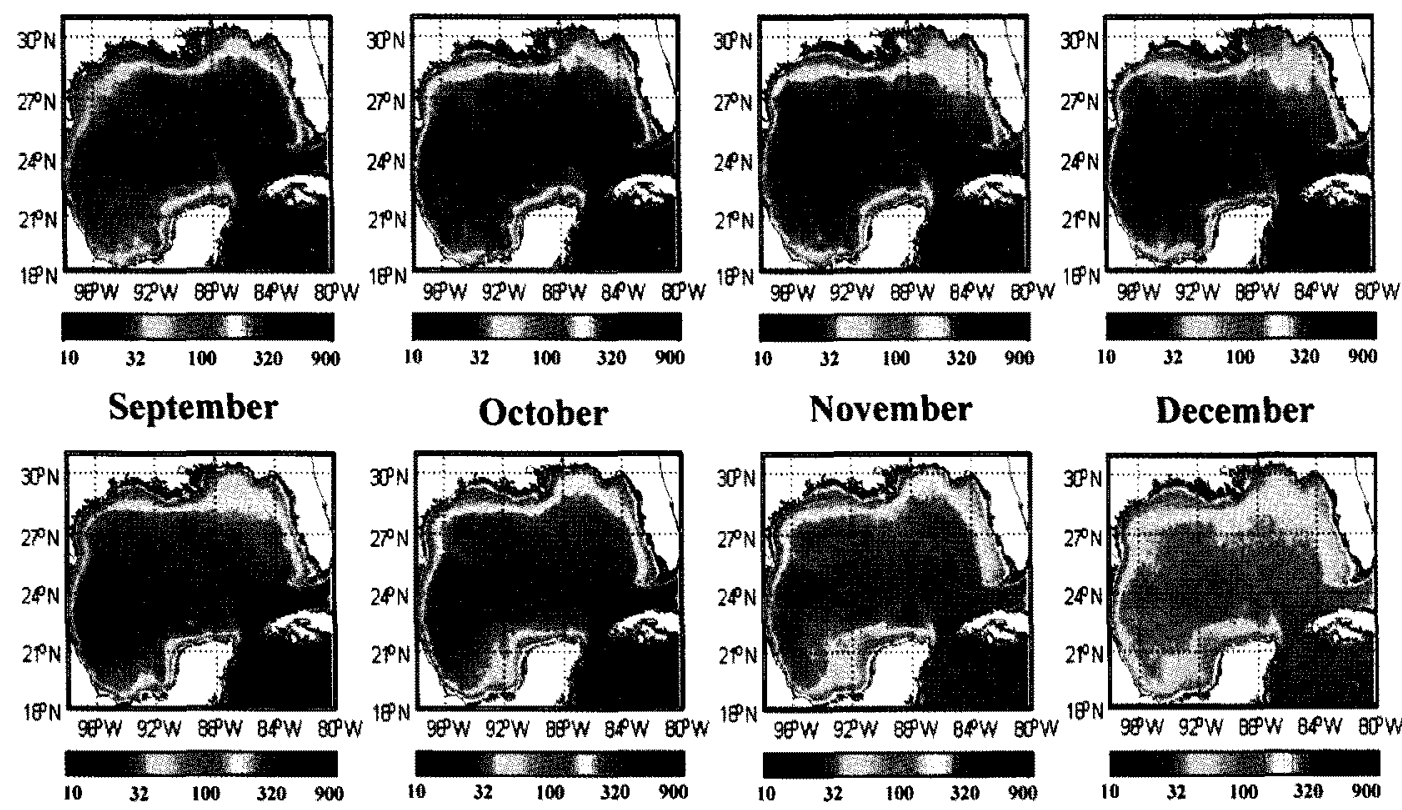

\section{December}

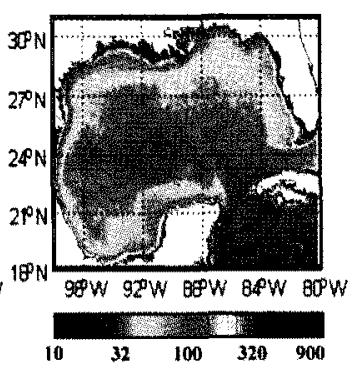

Fig. 2. Climatological monthly mean of particulate organic carbon(POC, $\left.\mathrm{mg} / \mathrm{m}^{3}\right)$ based on SeaWiFS radiance data in the Gulf of Mexico(September 1997 - December 2004).

The monthly mean of SST derived from NOAA AVHRR images for the period of September 1997 to December 2004 showed a north-south gradient, approximately parallel to the coast, with temperature diminishing northward(data not shown here). Winter(December-February) SST had a definite regional signature and wide range(February SST ranged from $15^{\circ} \mathrm{C}$ to $26^{\circ} \mathrm{C}$ ), while summer SST was more uniform and warmer(August mean SST was $29^{\circ} \mathrm{C}$ ). Cold surface water was constrained to the inner shelf of the northern Gulf of Mexico, generated by surface cooling, coastal upwelling, and runoff along the coast. Inflow of the warm LC was best observed during winter month, although the flow presented year round.

The monthly mean of dynamic SSHA archived from TOPEX/POSEIDON and Jason-1 altimeters for September 1997 to December 2004 determined mesoscale circulation patterns in the Gulf of Mexico(data not shown here). The monthly mean values did not adequately explain the description of either their continued evolution or motion. Cyclonic 
and anticyclonic eddies that were shed periodically from the Loop Current showed a chaotic distribution.

The monthly mean of SSW derived from QuickScat and SSM/I scatterometers for September 1997 to December 2004 determined much lower winds in summer than winter(data not shown here). In spring, a west wind prevailed in the central Gulf of Mexico, and the northwest/southwestward wind dominated in the northern Gulf of Mexico. During summer, winds were weak in the Gulf of Mexico and westward in the central Gulf of Mexico and north/northeastward in the northern Gulf. During fall, winds increased and shifted to the southwestward in the northern Gulf of Mexico. During winter, a south/southwestward wind dominated in the Gulf of Mexico.

Monthly PR based on SSM/I scatterometer satellite data for September 1997 to December 2004 showed that rainfall was focused on the northeastern Gulf of Mexico from January to April. Rain was heaviest through the Gulf in September, tapered in October, and was fairly uniform, but moderate in November and December(data not shown here).
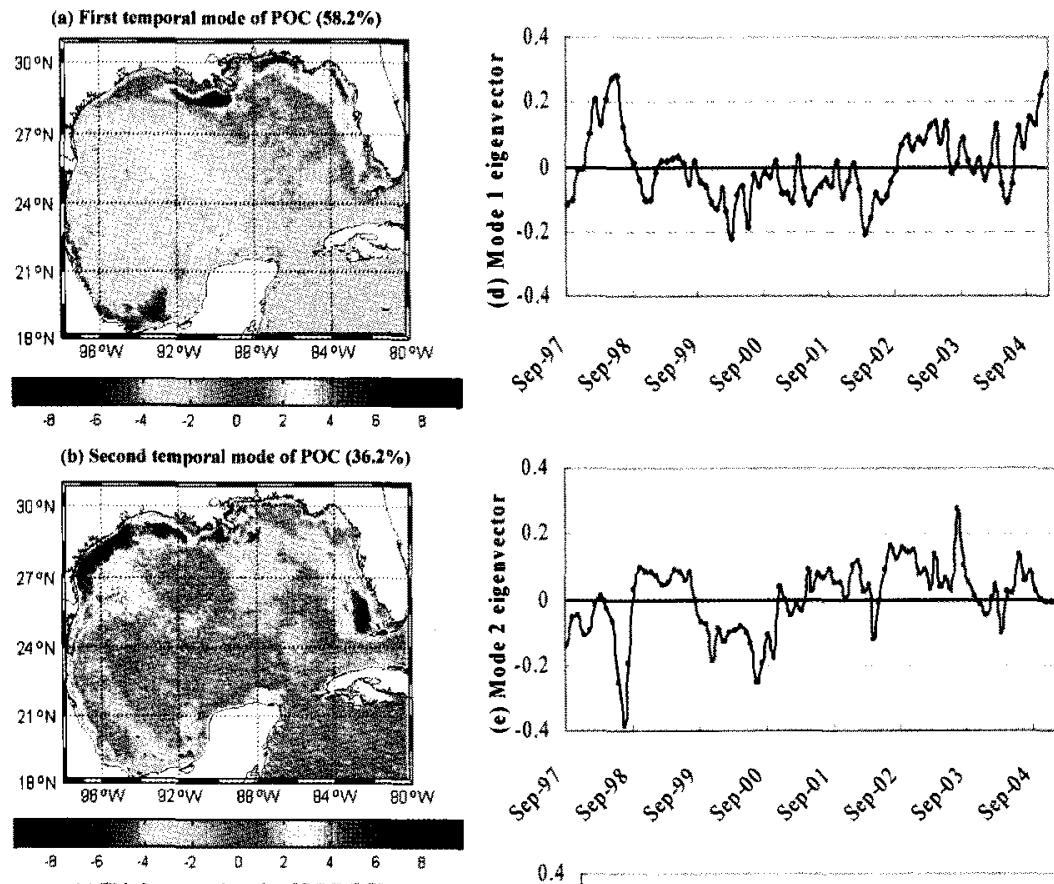

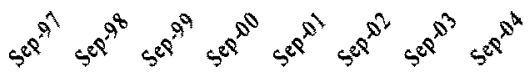
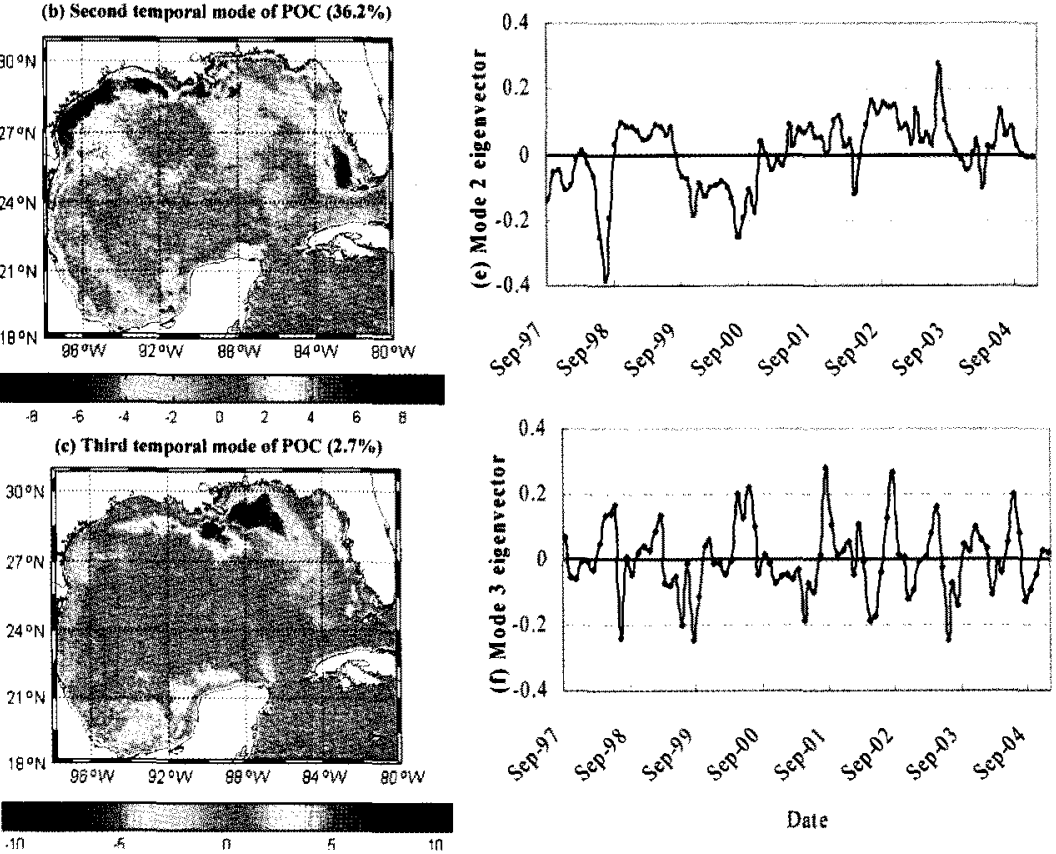

Fig. 3. Temporal modes of POC for EOF patterns(left) and their time series(right) in the Gulf of Mexico. 

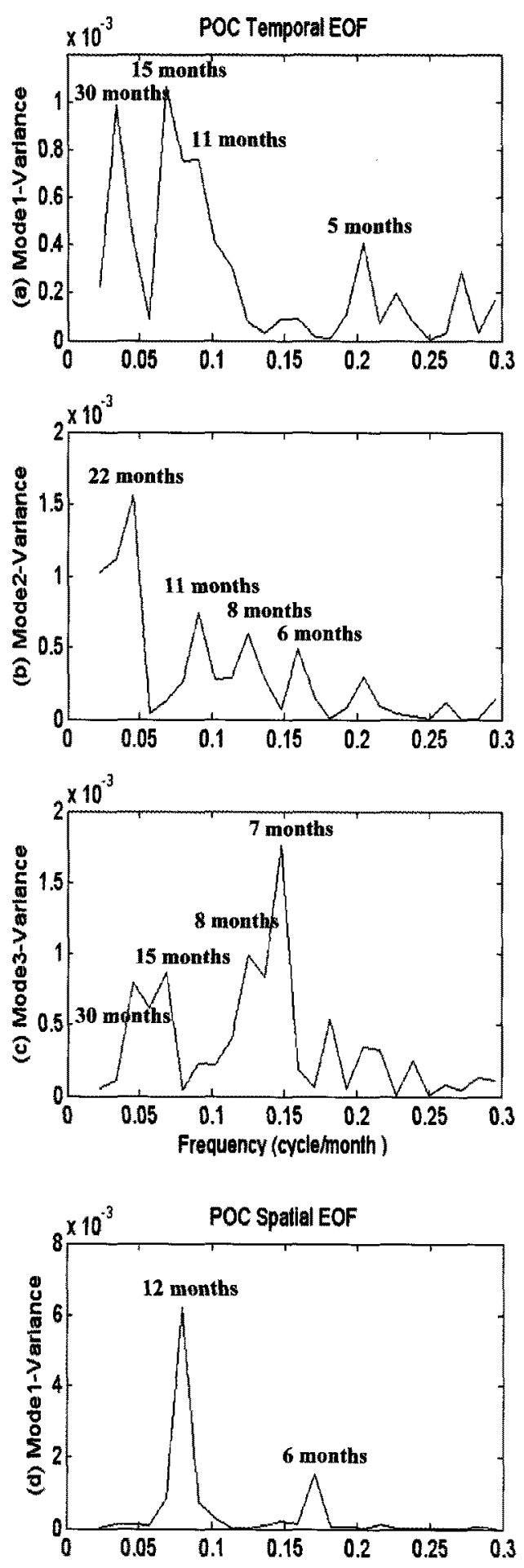

Fig. 4. Power spectra of time series in POC temporal and spatial modes of Figs. 3 and 5.

\section{2) Single EOF Analysis for POC Estimate - Spatial and Temporal Variations}

In the POC eigenvalues for the temporal variance EOFs, the first three modes accounted for approximately $97 \%$ of the total monthly POC variance(Fig. 3). The spatial pattern of the first temporal mode showed strong positive values along the inner shelf and near the Mississippi River in the northeastern Gulf of Mexico. Negative values were found in the southwestern Gulf of Mexico(Fig. 3a). Positive POC values in the time series of the first temporal mode were observed for most of 1998 and 2003-2004. Periods of negative anomalies occurred in 2000-2002(Fig. 3d). This time-series pattern was related to a non-seasonal cycle. The power spectrum provided that the first temporal mode had two strong peaks at frequencies of 30 and 15 months. The rest of the frequency was mostly constant and had a small peak at 5 and 11 months(Fig. 4a).

The spatial pattern of the second temporal mode exhibited an east-west trend(Fig. 3b). Positive POC vales in time series of the second temporal mode were observed for 1999 and 2001-2004, and negative values for 1997-1998 and 2000(Fig. 3e). The power spectrum provided that a strong peak was at a period of 22 months, and small peaks at periods of 6,8 , and 11 months(Fig. 4b).

The spatial pattern of the third temporal mode showed both positive and negative variance near the Mississippi River Delta(Fig. 3c). Positive values were observed on the west pass of the Mississippi Delta and negative value in the east pass of the Mississippi Delta. The power spectrum showed that time series of the third temporal mode had a strong peak at 7 and 8 months and weak inter-annual cycles(15 and 22 months, Fig. 4c),

The POC first mode of the spatial variation EOFs had a dominant annual component and a weak semi- 
(a) First spatial mode of POC $(99.8 \%)$
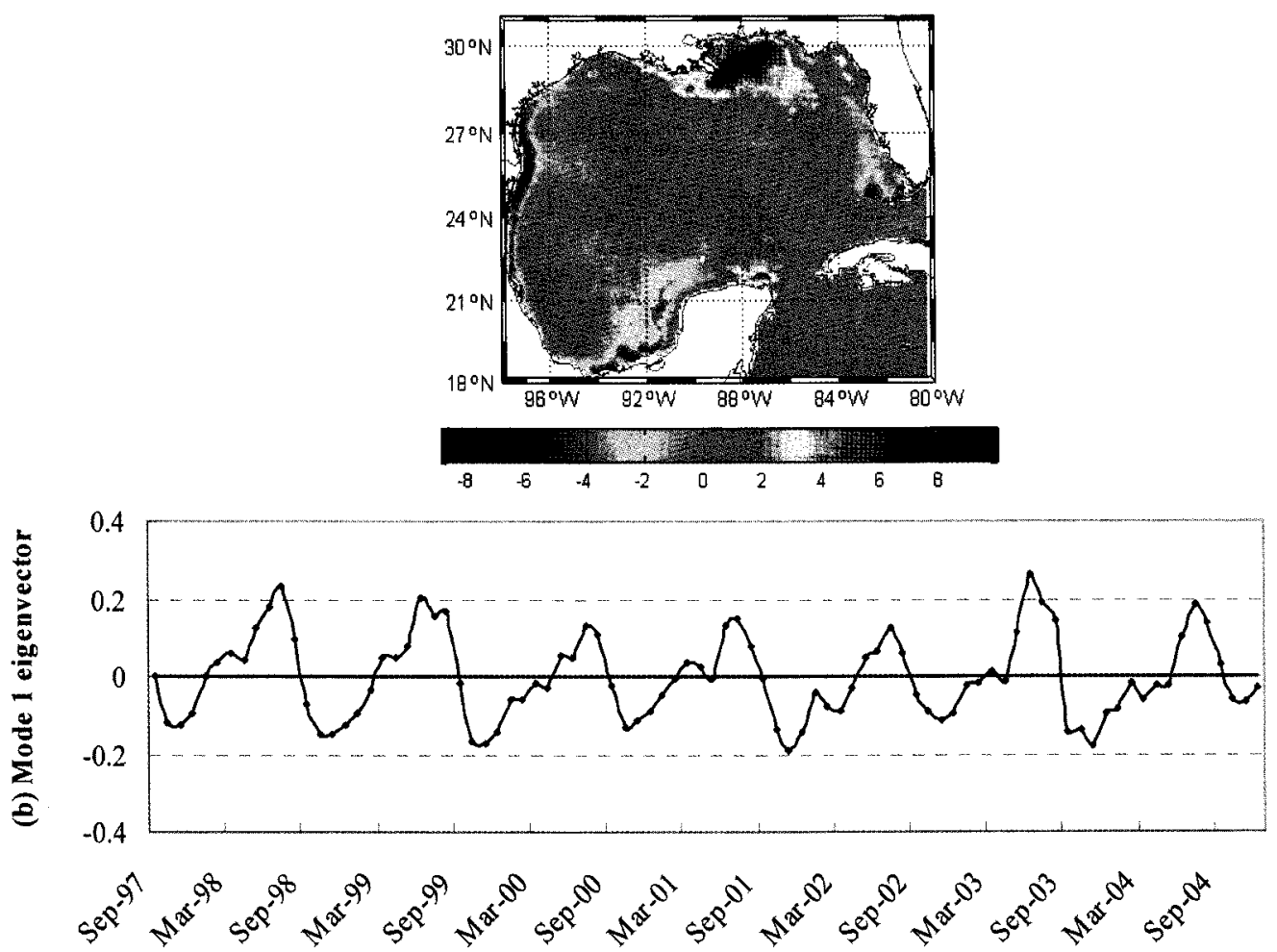

Date

Fig. 5. First spatial mode of POC for EOF pattern (a) and its time series (b) in the Gulf of Mexico.

annual period( $99 \%$ of total variance), with a maximum in Jun-July and a minimum in OctoberNovember(Figs. 4d and 5). It was the only statistically significant mode. The second and third spatial modes of POC explained about $0.1 \%$ of the total variance.

\section{3) A Coupled Relationship of Satellite Data Sets using CEOF}

The first three modes of POC and SST CEOF were dominant, which accounted for approximately $48 \%$, $20 \%$, and $10 \%$ of the total variance(Fig. 6). The first mode showed a significant relationship between POC and SST and the highest correlation of any of the satellite data coupled correlations(SSHA, SSW, and
PR).

There were two differences in the spatial CEOF patterns of POC and SST(Fig. 6). First, significant POC variations were observed along the shallow water(Case II water). Second, moderate POC variations were linked to offshore(Case I water). In SST fields, spatial amplitudes were related to the strength of the cold and warm water. Remnant cold water was observed close inshore. Warm water was associated with the LC and LCEs found offshore (Figs. 6d, 6e, and 6f). Positive POC values in the spatial pattern were negatively correlated with SST values. When positive POC values were observed along the shelf, SST values were negative(Figs. 6a, $6 \mathrm{c}, 6 \mathrm{~d}$ and $6 \mathrm{f})$. 
(a) First mode of POC CEOF (48.4\%)

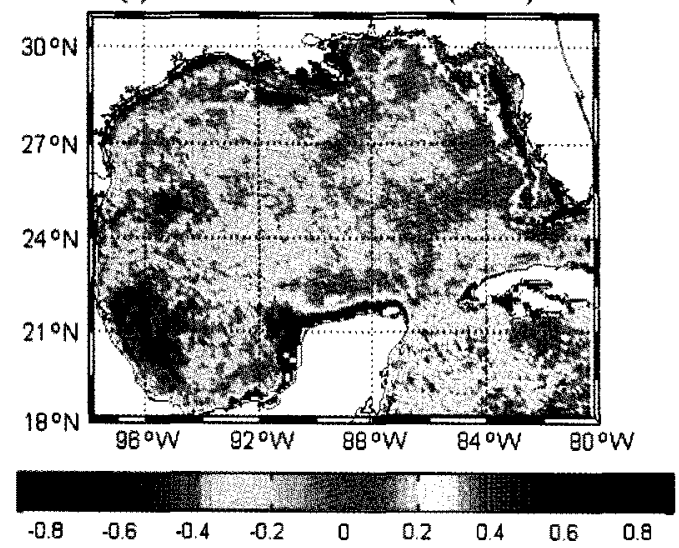

(b) Second mode of POC CEOF (20.3\%)

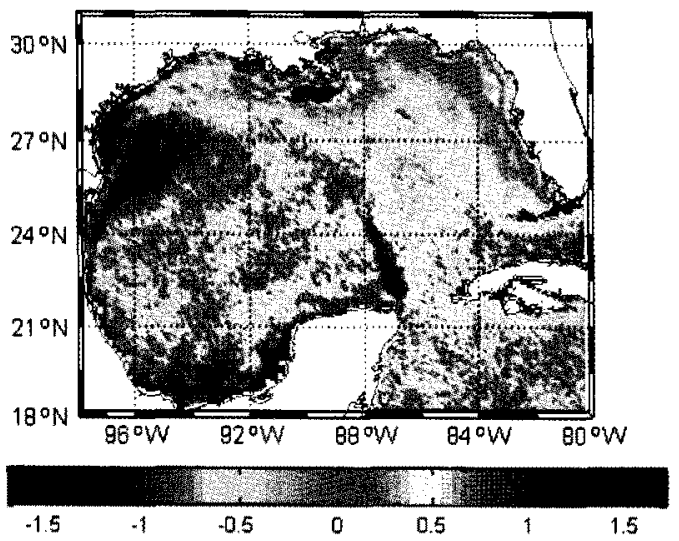

(c) Third mode of POC CEOF $(9.6 \%)$

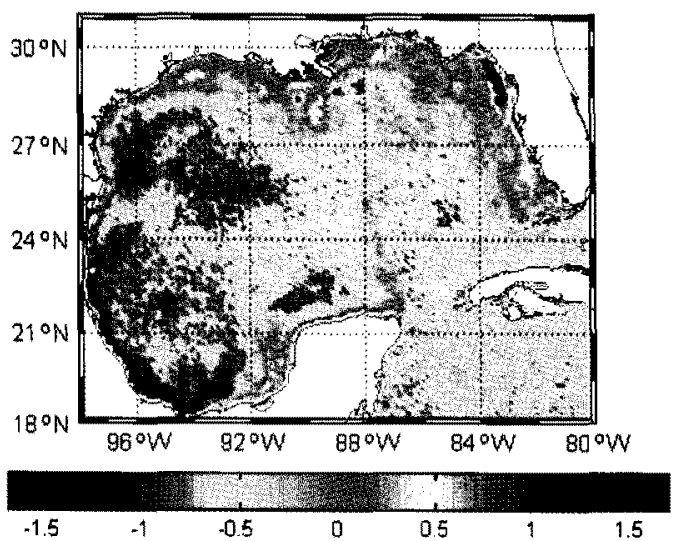

(d) First mode of SST CEOF $(48.4 \%)$

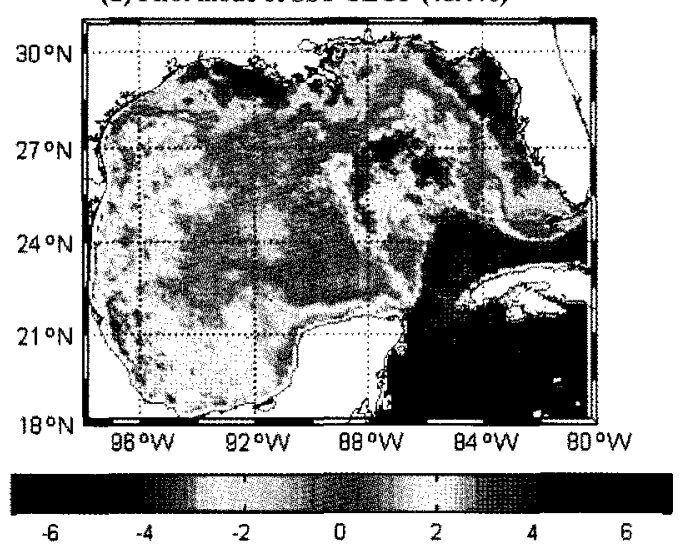

(e) Second mode of SST CEOF (20.3\%)
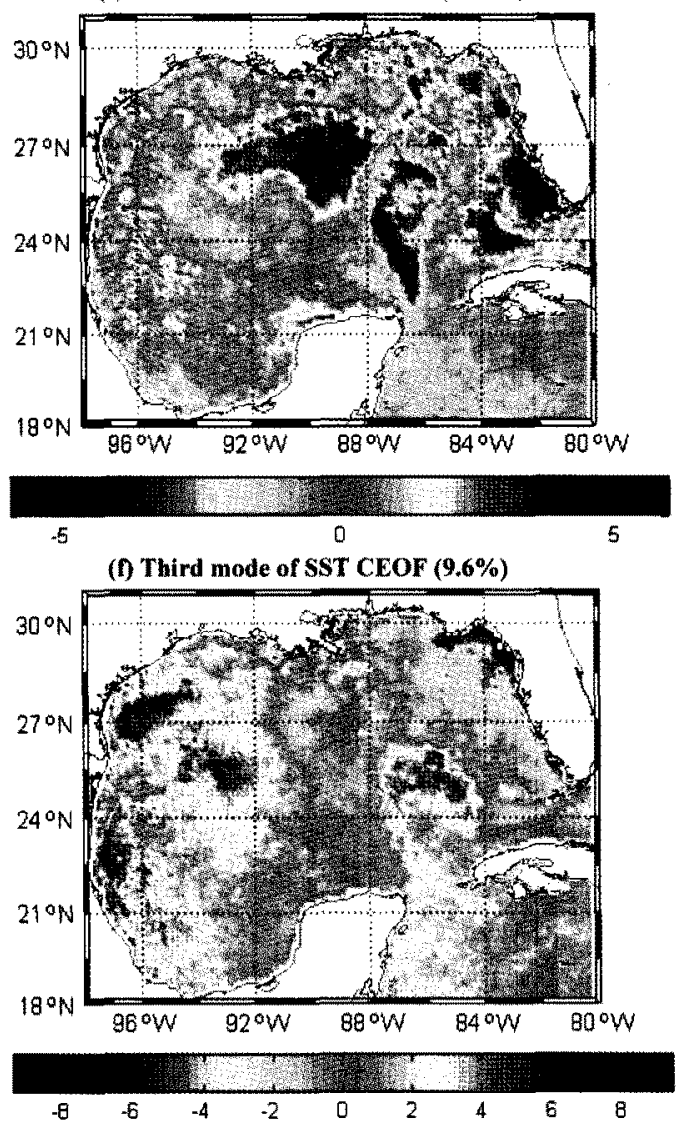

Fig. 6. Spatial patterns of POC and SST CEOF analysis in the Gulf of Mexico.

In the time series, positive eigenvectors in the first mode of POC and SST CEOF were observed in 1997-1998 and 2001, and negative values in 1999-
2000 and 2002. Values fluctuated about year in $2003-$ 2004(Fig. 7a). Positive eigenvectors in the second mode of POC and SST CEOF were found in 1997. 

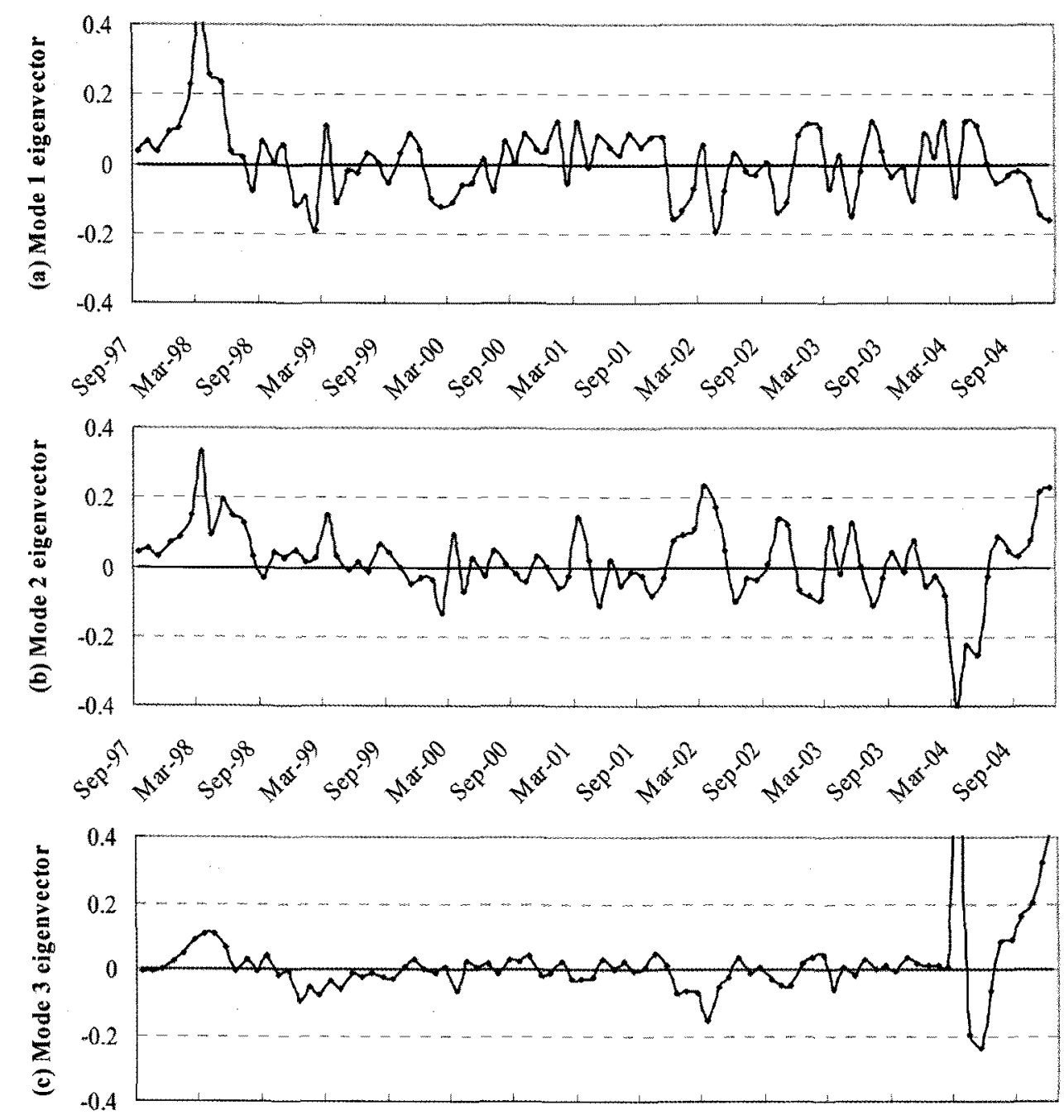

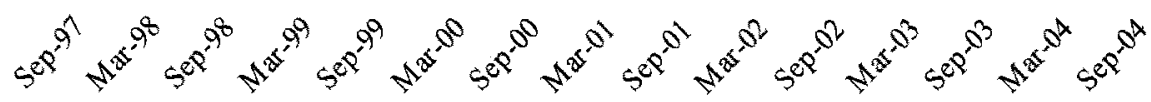

Date

Fig. 7. Time series of POC and SST CEOF modes in Fig. 6.

1999(Fig. 7b). The rest of time series values were fluctuated. During 1998-2003, positive peaks occurred in March. During 2004, a large negative peak occurred in March(Fig. 7b). Two large positive and one negative peak occurred in the third mode of POC and SST CEOF(Fig. 7c).

In this study, the first three modes of POC and SSHA CEOF accounted for $35 \%, 14 \%$, and $11 \%$ of the total variance(Fig. 8). The spatial pattern in POC and SSHA CEOF showed significant features offshore. When SSHA was negative, POC was positive. When SSHA was positive, POC was negative. Negative and positive values of SSHA in the spatial pattern were related to the Loop Current and eddies(Son and Gardner, 2010). POC in the open ocean seemed to be dependent on large-scale 
(a) First mode of POC CEOF (34.5\%)

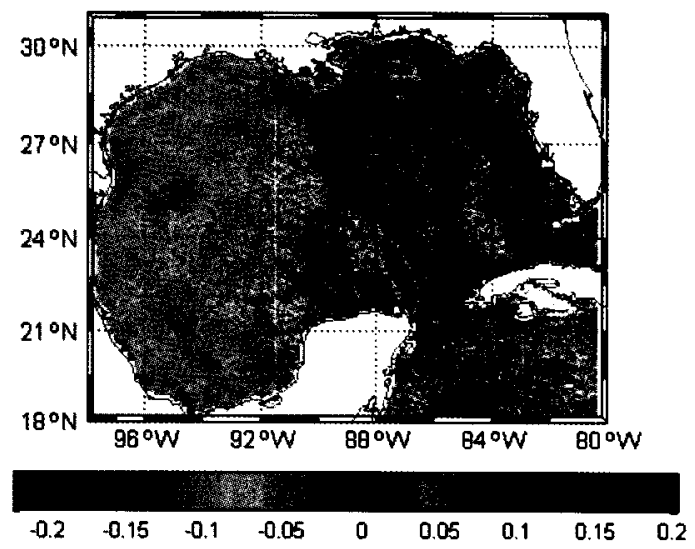

(b) Second mode of POC CEOF (13.6\%)
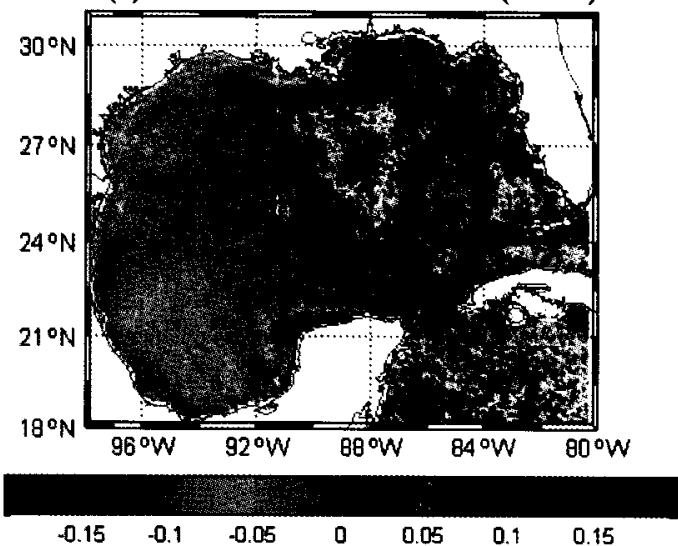

(c) Third mode of POC CEOF (11.2\%)

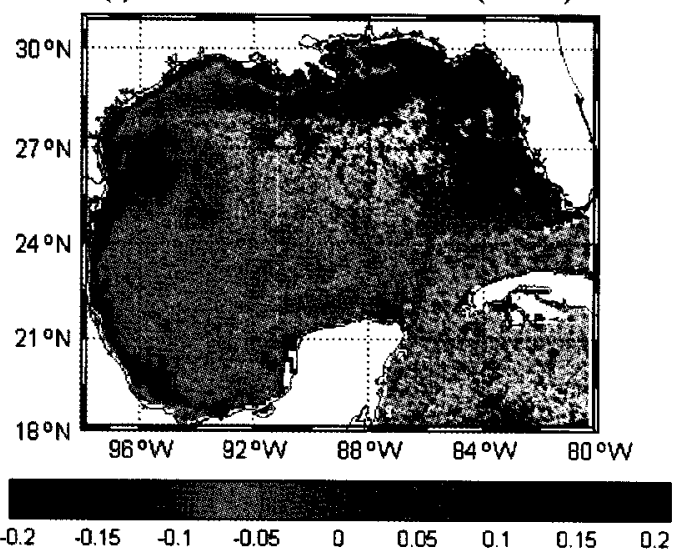

(d) First mode of SSHA CEOF (34.5\%)

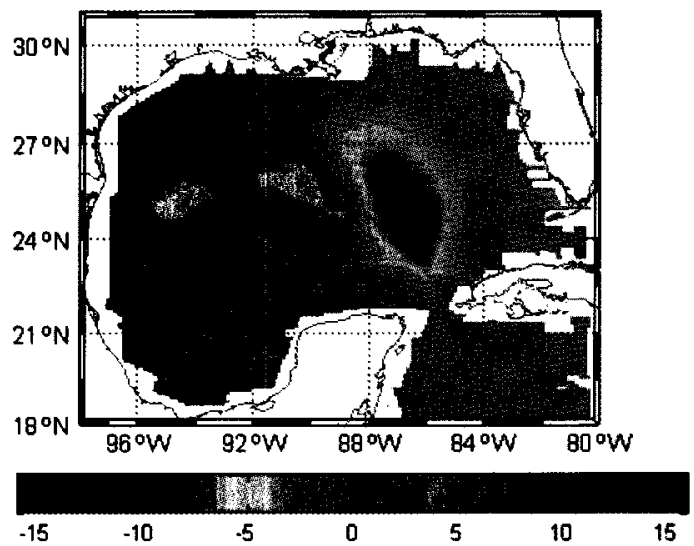

(e) Second mode of SSHA CEOF (13.6\%)

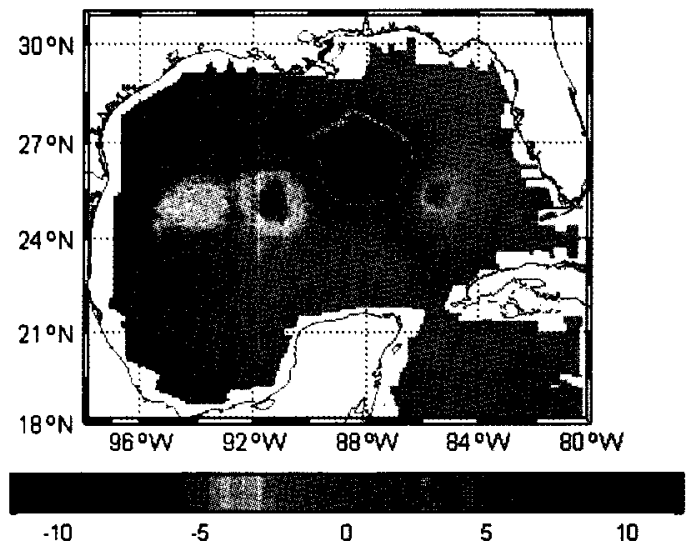

(f) Third mode of SSHA CEOF (11.2\%)

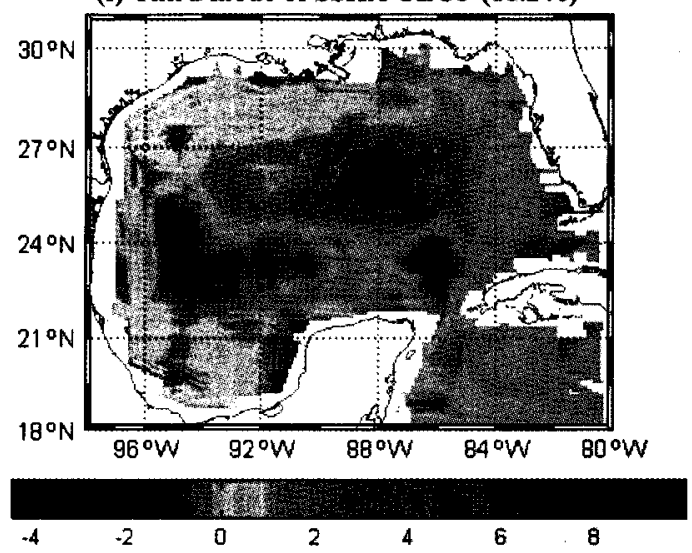

Fig. 8. Spatial patterns of POC and SSHA CEOF analysis in the Gulf of Mexico.

circulation(Fig. 8). In time series, positive values in the first mode of POC and SSHA CEOF were observed during 1997-1998 and 2002, and negative values for 1999-2001 and 2003(Fig. 9a). Values in the second mode of POC and SSHA CEOF fluctuated throughout the 7 years(Fig. 9b). Strong 

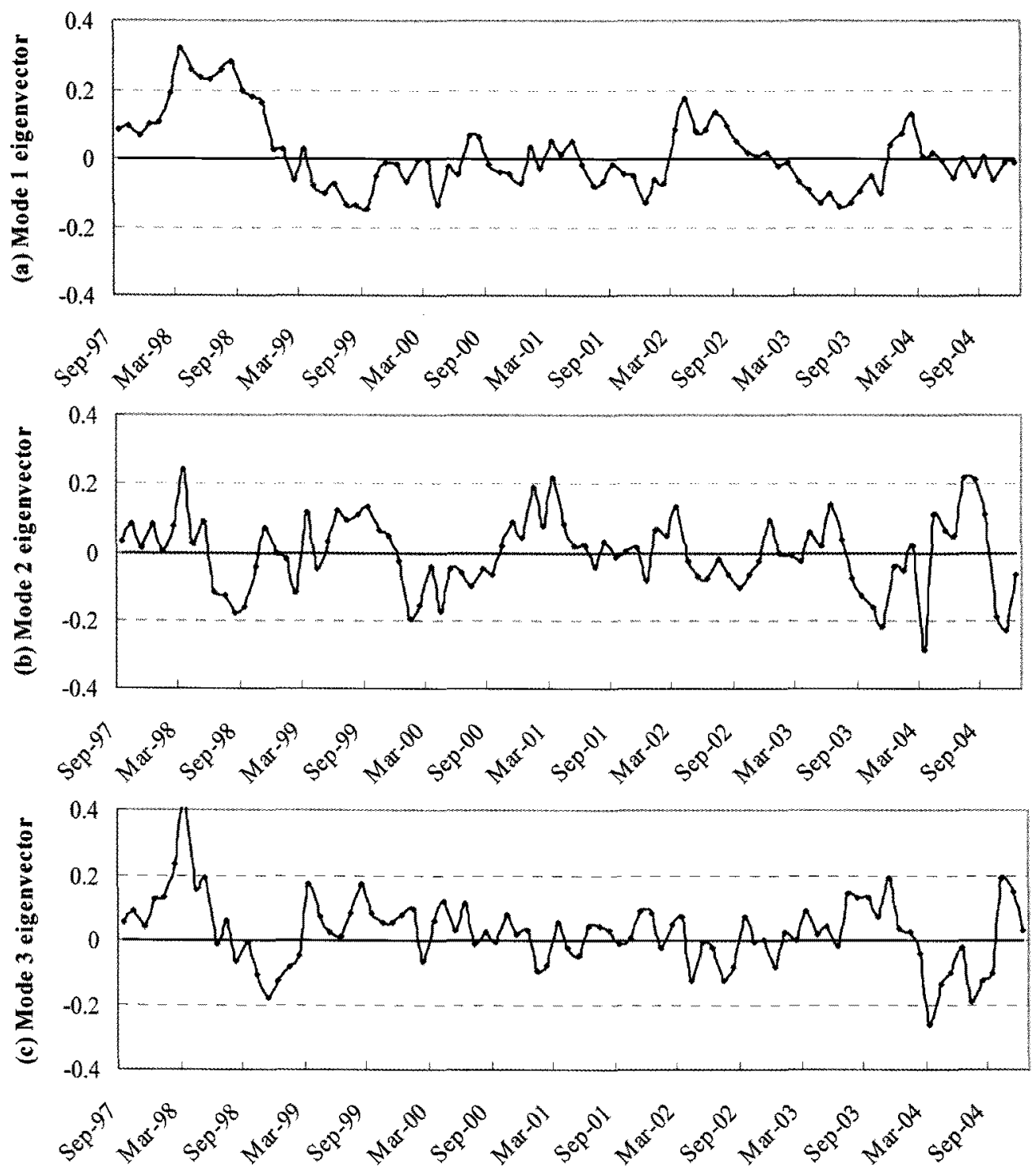

Date

Fig. 9. Time series of POC and SSHA CEOF modes in Fig. 8.

positive values in the third mode of POC and SSHA CEOF occurred in 1998 and the largest negative value in 2004. Most of the time series data fluctuated about year(Fig. 9c).

The first three modes of POC and SSW CEOF accounted for about $37 \%, 32 \%$, and $9 \%$ of the total variance(Fig. 10). In the spatial distribution of the first mode, positive POC values were observed on the eastern Gulf of Mexico with positive southwest winds and negative POC values on the western Gulf of Mexico(Figs. 10a and 10d). In the spatial pattern of the second and third modes, positive POC values were constrained to the inner shelf with dominant southeastward winds, but their amplitudes were 
(a) First mode of POC CEOF (36.7\%)

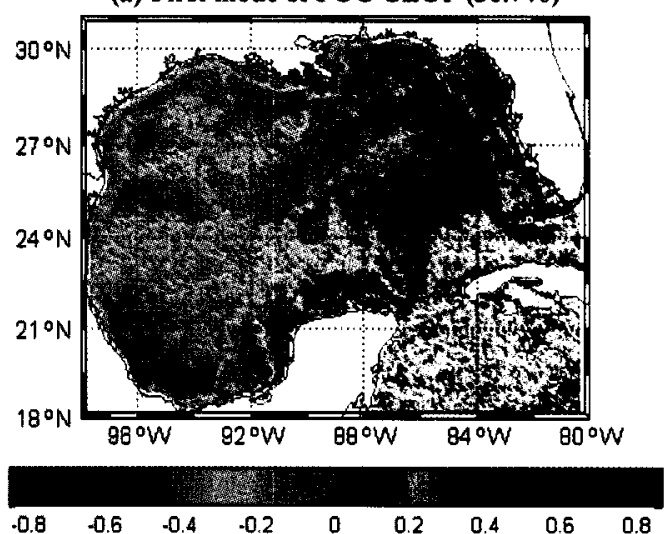

(b) Second mode of POC CEOF (31.7\%)

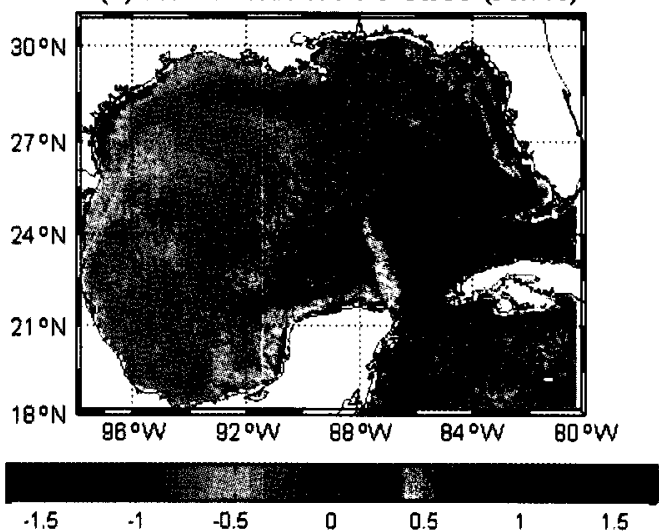

(c) Third mode of POC CEOF $(9.1 \%)$

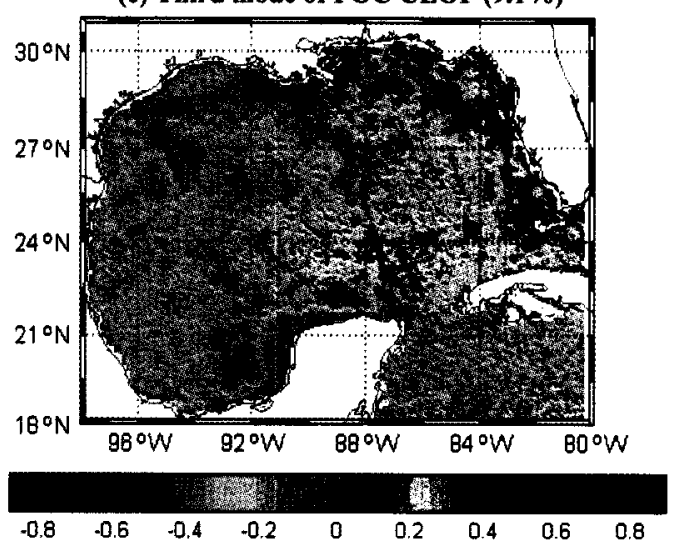

(d) First mode of SSW CEOF (36.7\%)

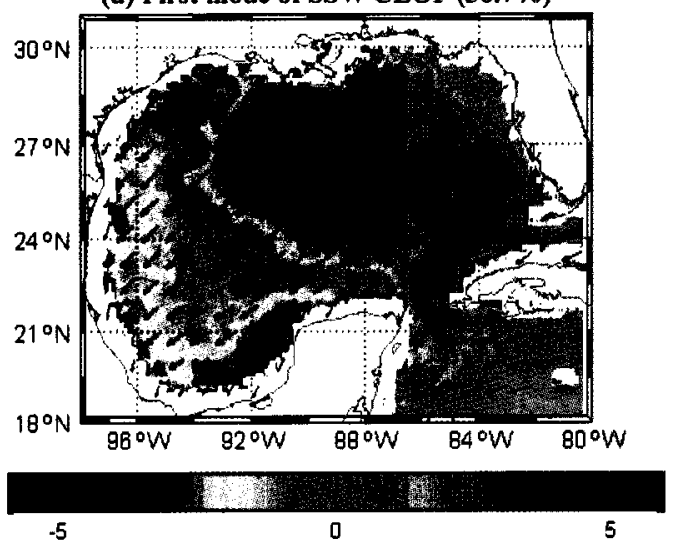

(e) Second mode of SSW CEOF

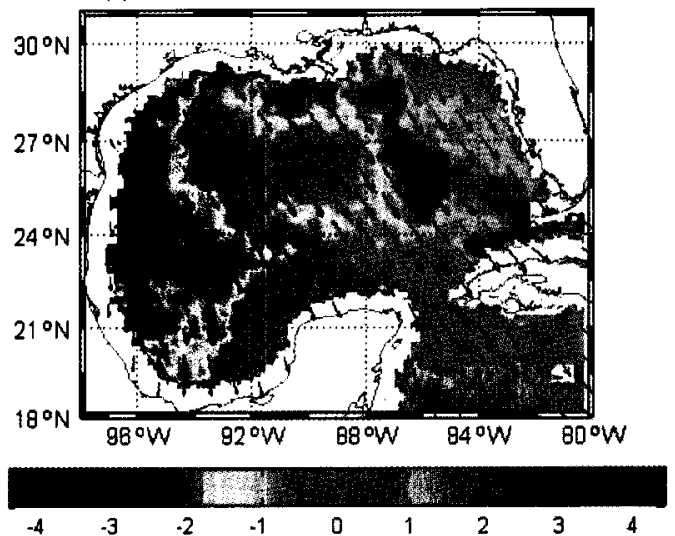

(f) Third mode of SSW CEOF (9.1\%)

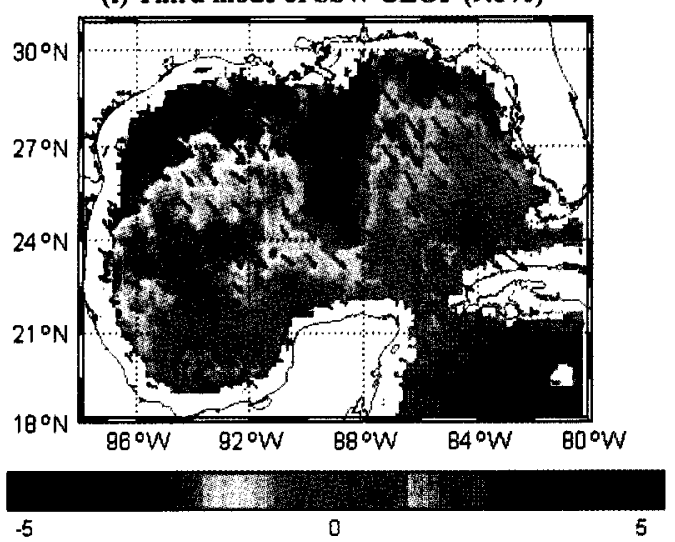

Fig. 10. Spatial patterns of POC and SSW CEOF analysis in the Gulf of Mexico.

changed with space(Figs. 10b, 10c, 10e, and 10f). Although time-series patterns in the first three modes of POC and SSW CEOF fluctuated, dominant positive values were observed in 1997-1998(Fig. 11). However, these results explained little of the physical process connecting POC and winds, especially 

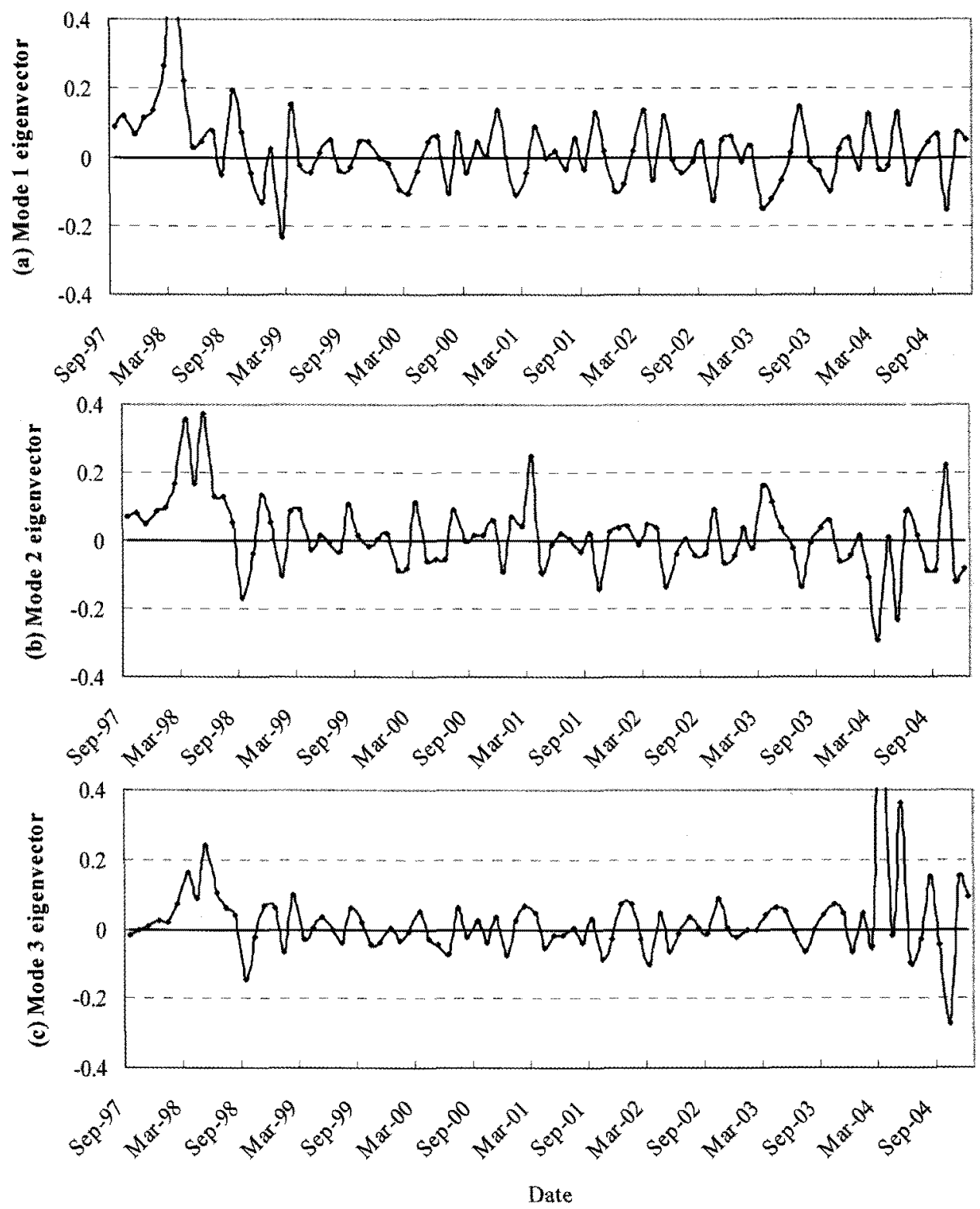

Fig. 11. Time series of POC and SSW CEOF modes in Fig. 10.

offshore. In general, the coastal circulation was driven by wind stress(Walker, 1996), but the openocean circulation in the Gulf of Mexico was affected by the Loop Current and eddies(Hofmann and Worley, 1986; Hamilton et al., 2002; Frolov et al., 2004).

The first three modes of POC and PR CEOF accounted for $42 \%, 29 \%$, and $6 \%$ of the total variance(Fig. 12). Positive PR values in the spatial pattern of the first and second modes were well correlated with positive $\mathrm{POC}$ values in the northern Gulf of Mexico(Figs. 12a, 12b, 12d, and 12e). Negative POC and PR values in the spatial pattern of the first and third modes were found on the 
(a) First mode of POC CEOF (41.9\%)

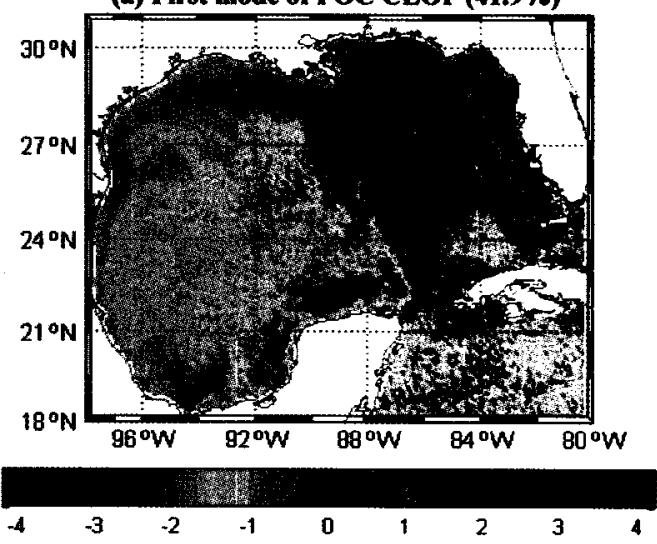

(b) Second mode of POC CEOF (28.7\%)

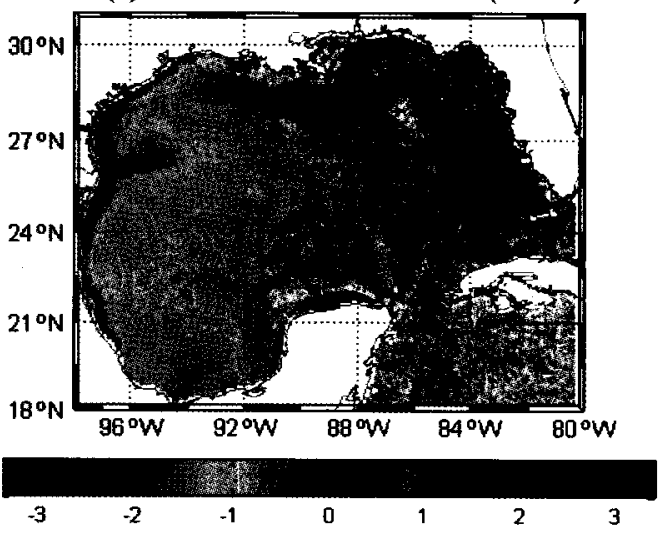

(c) Third mode of POC CEOF (6.0\%)

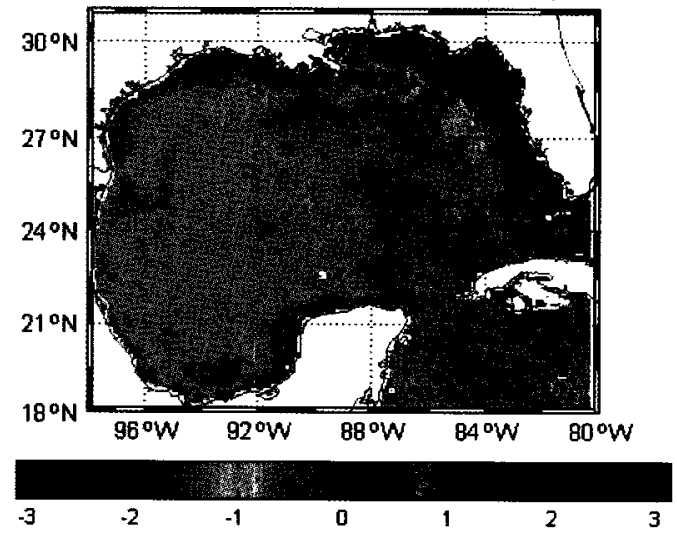

(d) First mode of PR CEOF (41.9\%)

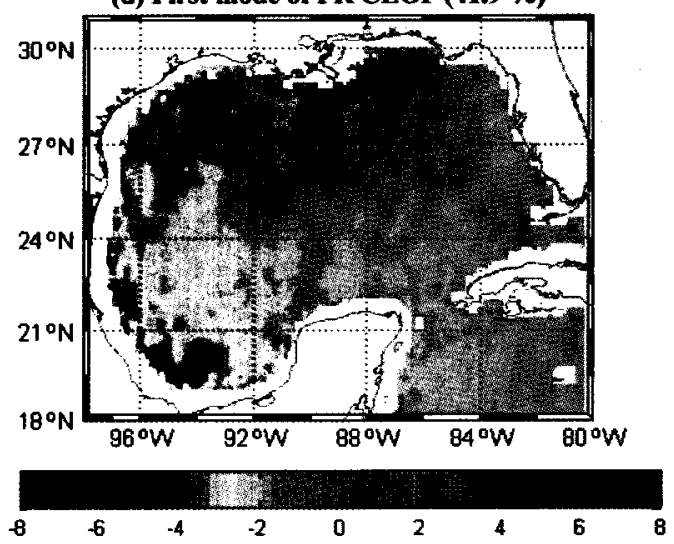

(e) Second mode of PR CEOF (28.7\%)

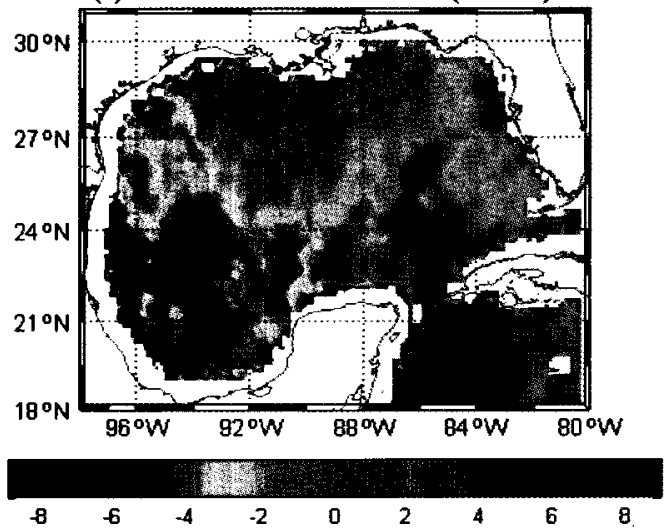

(f) Third mode of PR CEOF (6.0\%)

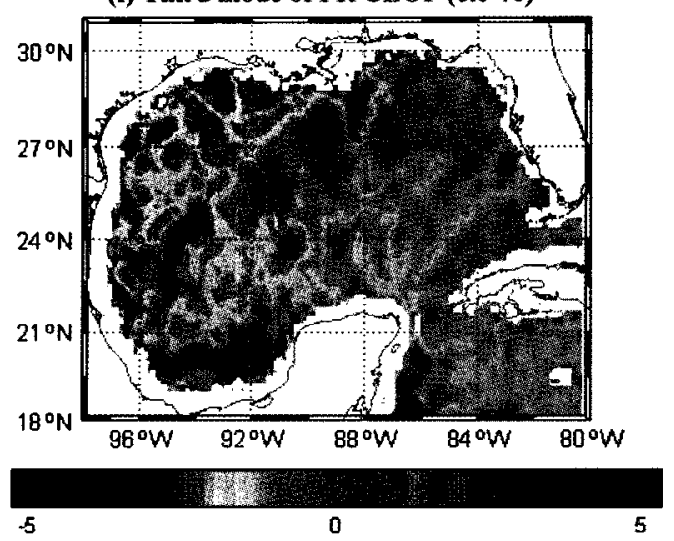

Fig. 12. Spatial patterns of POC and rainfall CEOF analysis in the Gulf of Mexico.

southwestern Gulf of Mexico(Figs 12a, 12c, 12d and 12f). During 1997-1998, higher rainfalls were observed at time series of the first three modes(Fig. 13). The higher rainfalls were directly/indirectly related to output of the major rivers and influenced POC concentrations in the study area. The times-series pattern of the first mode was similar to the anomaly of river discharge in the northeastern Gulf of 

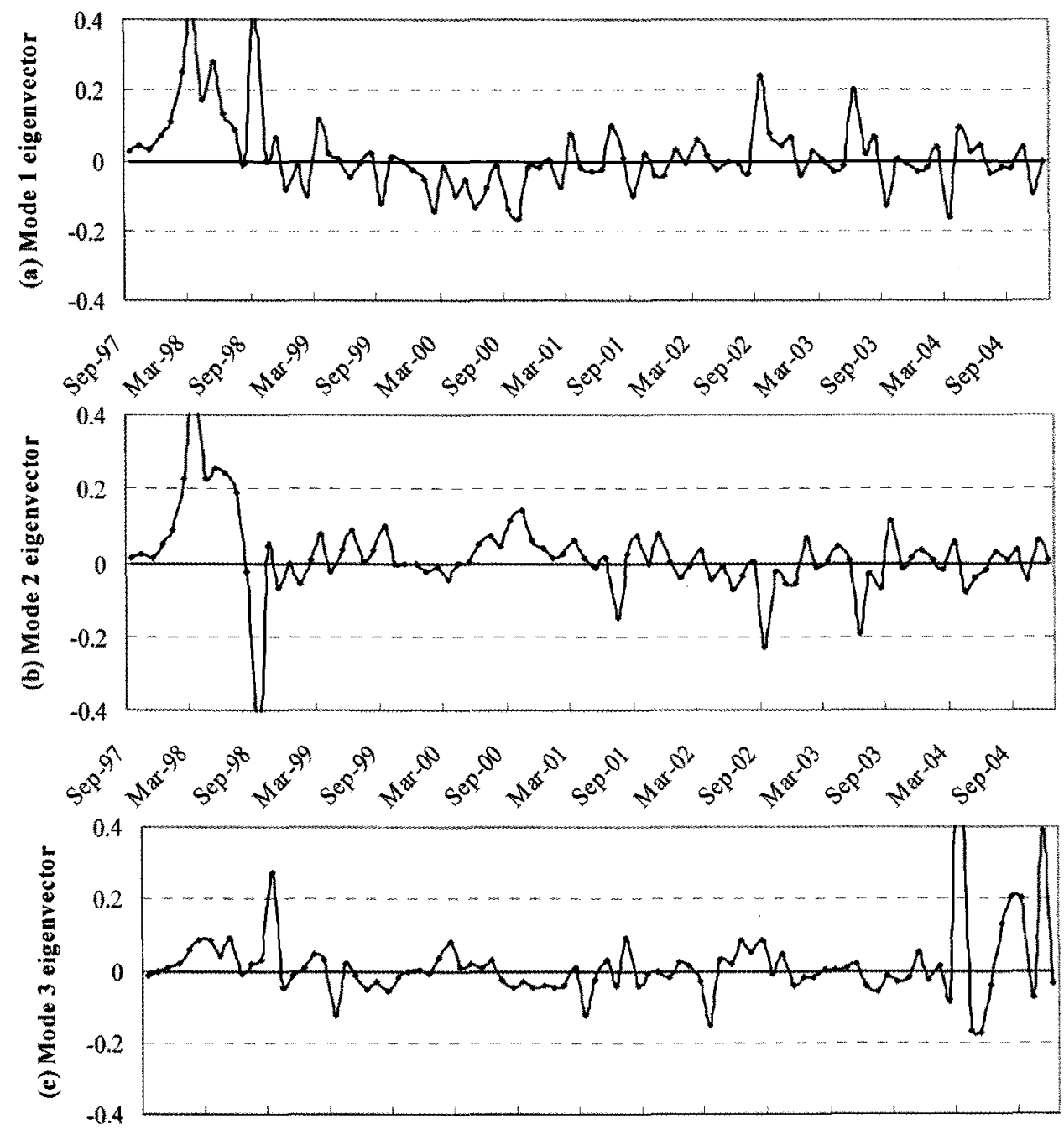

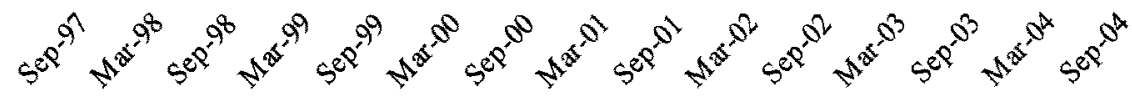

Date

Fig. 13. Time series of POC and rainfall CEOF modes in Fig. 12.

Mexico(Son, 2006; Son and Gardner, 2010, Fig. 13a).

\section{Discussions}

EOF analysis is a statistical method used to decompose a multi-variant data set into its principal components. Using this method, the bulk of the variance of a data set can be described by a few orthogonal modes, so that the major properties of the data set can be more easily understood(Preisendorfer, 1988; Emery and Thomson, 1997; Thomas et al., 2003; Son, 2006). While EOF analysis is applicable to the time-dependent spatial fields of a single variable, CEOF analysis is a means of decomposing the time dependent spatial fields of two variables so 
that the two resulting spatial patterns have the maximum possible temporal correlation for any particular mode. This approach is useful for studying the temporal variability of two separate but related oceanographic fields(Frankignoul et al., 1996).

In this study, single and combined EOF analysis were used to investigate the temporal and spatial variations of POC and to determine the physical processes that affect the temporal and spatial distribution of POC in the Gulf of Mexico. The temporal and spatial POC variations based on the EOF analysis suggested four general patterns and/or variations in the Gulf of Mexico. First, higher POC variations were observed along the coastal regions. Second, higher POC variations were related to the direction of the river discharge, especially near the Mississippi and Alabama Rivers. Third, POC variations were linked to the mesoscale circulation offshore. Fourth, surface POC variations were connected with inter-annual large scale processes.

First, POC values were elevated in shallow water along the western and eastern Gulf of Mexico(Figs. $3 a$ and $3 b$ ). Maximum and minimum values of POC in time series of the first temporal mode were observed in the spring/summer and fall/winter seasons(Figs. 3a and 3d). Son and Gardner(2010) suggested that spatial patterns of higher surface POC concentrations were associated with the input of fresh water, stratification of the water column, and regional circulation patterns in the northern Gulf of Mexico. Along the shelf of the northeastern Gulf of Mexico, positive values of POC concentrations and negative values of SST in spatial patterns of the first mode had maximum peaks in the early spring(Figs. 6a, 6d, and 7a). Higher POC concentrations were followed by cold water during the spring, which produced the nutrient-rich inshore waters. Most major rivers are concentrated in the northern Gulf of Mexico and higher river discharges occur during the spring(Son,
2006; Son and Gardner, 2010). Time series patterns in the first mode of POC and SST CEOF were similar to the time-series pattern of river discharge. Although river discharge increased during the spring, strong wind speed caused increasing vertical mixing, reducing stratification and higher particulate matter(PM) and POC concentrations were constrained to the shelf rather than spreading laterally. During the late spring and summer seasons, stratification of the water column and the buoyancy forcing of fresh water increased. The warm, fresh water easily spread out across the surface. This pattern diminished from fall to early spring(Son, 2006; Son and Gardner, 2010). However, spatial correlation of $\mathrm{POC}$ and rainfall was positive along the northern Gulf of Mexico, especially near the Mississippi Delta(Figs. 12a and 12d). Higher rainfall increased river discharge to the northern Gulf waters, which transported more particles and nutrients to shallow water during 1997-1998(Fig. 13).

Second, the variation of POC concentrations showed dispersion of the east-west trend near the Mississippi and Alabama region. In the third temporal mode of POC, the positive and negative amplitudes showed inverse signals in the east and west passes of the Mississippi Delta(Fig. 3c). Dispersion of fresh waters in the west passes of the Mississippi Delta was controlled by wind stress(Walker, 1996). Dispersion of fresh waters in the east passes of the Delta was affected not only by wind stress but also by buoyancy forcing and the general circulation system(Walker, 1996; Morey et al., 2003). The results of a numerical model by Morey et al. (2003) showed pathways of the river discharge of the major rivers in the northern Gulf of Mexico. Their results also suggested that the local wind stress caused the export of the fresh water toward the east in the late spring and summer seasons. However, the annual cycle of POC 
concentration in the inshore was affected by fresh water, and the dispersion of high concentration water was influenced by the annual cycle of the local wind stress(Morey et al., 2003). Spatial correlation of POC and SSW was largely defined in two directions. Southwest-ward winds were dominant in mode 1 , southeast-ward winds in modes 2 and 3. Positive values in the first mode were observed in the central Gulf of Mexico and southwest-ward winds helped water and PM move seaward. Second and third modes had a weak influence on dispersion highconcentration POC waters(Fig. 10).

Third, a limited dispersion of POC was generally associated with the LC and LCEs. Wind stress contributed to the shelf circulation on the Gulf of Mexico, but the LC and LCEs were the dominant mechanism over the open ocean(Hamilton et al., 1999, 2002; Sturges and Leben, 2000; Frolov et al., 2004). Morey et al. (2003) inferred that fresh water was transported offshore by the mesoscale eddies. Large anticyclonic eddies a periodically pinched off from the LC at intervals from 3 to 17 months and move westward(Sturges and Leben, 2000). This circulation pattern can be observed in SST and SSHA images(Figs. 6 and 8). The spatial pattern in POC and SSHA CEOF showed the relationship between POC concentrations and the LC and LCEs. Negative SSHA values were associated with positive POC values. Positive SSHA values were related to negative $\mathrm{POC}$ values(Fig, 8). However, the first and second modes of POC and SSHA CEOF showed interesting spatial patterns, which POC distribution could be affected by anticyclonic and cyclonic flows. Strictly speaking, SST and SSHA did not present directly the physical factors for controlling POC estimates, but these spatial patterns show circulation patterns offshore. Development of anticyclonic circulation tended to diminish POC concentrations and underdevelopment of anticyclonic circulation tended to increase POC concentrations. These relationships point to important physical processes in the study area(Son and Gardner, 2010).

Fourth, the non-seasonal time-series indicated that POC concentration was strongly affected by the enhancement of large-scale processes. To better understand what happened from September 1997 to December 2004, time series of EOF analysis of monthly satellite images(POC estimates, SST, SSHA, SSW, PR, and river discharge) defined the seasonal and non-seasonal components(Son, 2006). Most time series of spatial variance consisted of semi-annual and annual peaks at 6 and 12 months(Figs. 3, 4, and 5). The amplitude of the non-seasonal time-series in EOF modes was higher than normal during 1997 1998 and 2003-2004 and lower during 1999-2001. In 2002 , the anomaly changed from negative to positive values. The non-seasonal peaks of POC had periods of 15,22 , and 30 months, and first mode showed a strong peak at 30 months(Fig. $4 a$ ). The low frequency signal in POC and physical forcing function was similar to EI Niño/Southern Oscillation(ENSO) events(Fig. 14), which are the most important coupled ocean-atmosphere phenomena to cause global climate variability on interannual time scales(Wolter and Timlin, 1998). El Niño events occurred during 1997-1998 and 2002-2004, and La Niña conditions existed during 1999-2001. During El Niño events, the eastern Gulf of Mexico was wetter than normal(Thurman and Trujillo, 2002). Positive values of river discharge and $\mathrm{POC}$ were observed for 1998 and 2003-2004 and negative anomalies for 1997 and 1999-2002. During periods of 1998 and 2003-2004, higher POC concentrations were observed along the northern Gulf shelf and lower POC concentrations along the southwest Gulf shelf. During periods of 1999-2002, higher POC concentrations were found along the southwestern Gulf shelf and relatively lower POC estimates along 

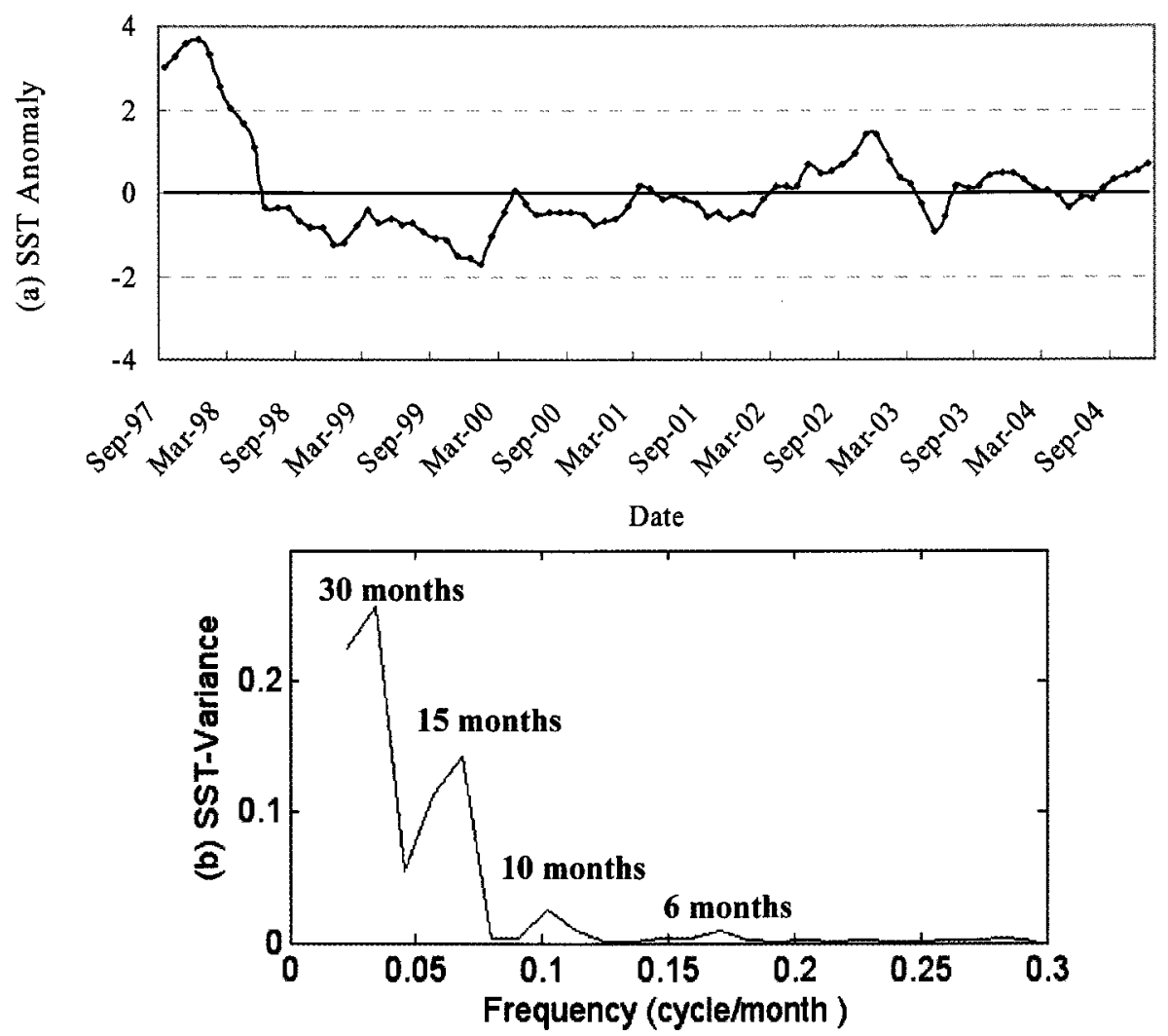

Fig. 14. (a) Sea surface temperature anomaly(SSTA) averaged over $[5 \mathrm{~S}, 5 \mathrm{~N}]$ and $[150 \mathrm{~W}, 90 \mathrm{~W}]$ during September 1997 and December 2004(the eastern equatorial Pacific) - an index that measures the strength of an ENSO event. (b) Power spectra of time series in SSTA of Fig. 14a.

the northern Gulf shelf. However, both signals were related to seasonal and inter-annual components. In the power spectrum analysis, the inter-annual cycle(30 months) of the river discharge in Florida corresponded well with the peak in the first temporal mode of POC(Figs. 4 and 15). Dominant peaks along Mississippi and Alabama showed inter-annual cycles, such as 18 and 22 months(Fig. 15). Time series of PR and river discharge from these data showed relatively positive amplitudes in the eastern Gulf Coast also. Higher runoff is consistent with positive POC amplitude along the shelf, because of high terrestrial/nutrient input(Son and Gardner, 2010). The western Gulf of Mexico was influenced by low rainfall(Thurman and Trujillo, 2002). Decreased river discharge was related to negative POC EOF amplitude along the coast, and was also related to low nutrient input.

However, the forces likely to govern climate variability are air-sea heat exchange and wind stress forcing expressed as upper-ocean temperature anomalies on interannual timescales(Miller et al., 1994; Frankignoul et al., 1996). Some studies proposed positive feedbacks between the atmospheric circulation and SST(Deser and Blackmon, 1993; Latif and Barnett, 1994). In this study, large-scale changes of SST suggested a coupled atmosphericocean circulation, and time series in the first three modes of SST reveal interannual variations in the Gulf of Mexico(Fig. 6). Moreover, variability 

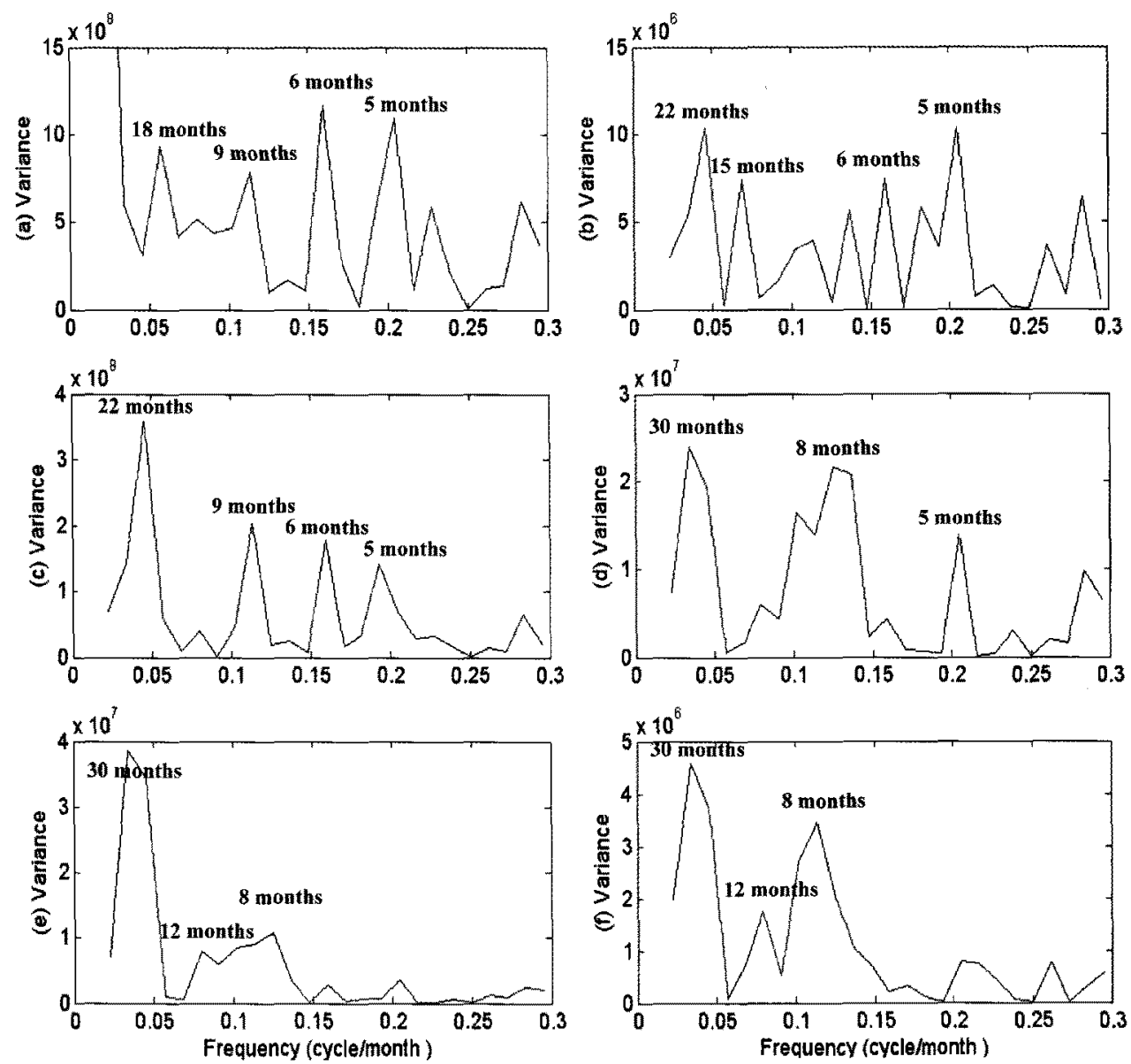

Fig. 15. Power spectra of time series in river discharge in Fig. 2.6. (a) the Mississippi River; (b) the Mississippi Area; (c) the Alabama Area; (d) the west Florida; (e) the middle Florida; (f) the east Florida.

between SST and SSHA were temporally and spatially correlated with large-scale fluctuations(Figs. 6-9). The spatial patterns of SST and SSHA offshore showed mesoscale circulation patterns in the Gulf of Mexico such as the anticyclonic Loop Current and its associated anticyclonic and cyclonic eddies. Although the Loop Current and eddies periodically evolved and detached from the LC, the influence of these eddies varied interannually in the Gulf of Mexico. Temporal and spatial surface POC concentrations may have been strongly affected by interannually varying oceanic circulation.
However, POC variability correlated with nonseasonal components could be explained by one or more combined physical factors such as SST, SSHA, SSW, and input of fresh water. To better understand these correlations, it is necessary to study large scale processes, such as coupled ocean-atmosphere forcing in the Gulf of Mexico. If this information was more complete, we could more clearly explain the relationship between POC variability and physical processes. 


\section{Conclusions}

In this study, using satellite estimates of POC, SST, SSHA, SSW, PR, and river discharge, temporal and spatial relationships between biological and physical processes, and their response to different oceanographic forcing were investigated. Analysis of a nearly seven-year time series(September 1997 December 2004) of satellite data throughout the Gulf of Mexico revealed seasonal and inter-annual cycles. Cycle amplitudes of POC were enhanced on the shelf and diminished offshore.

Higher POC concentrations occurred in the eastern Gulf coast during summer, but in the western Gulf coast during spring. Higher POC values inshore were concentrated on the northern Gulf of Mexico. It appeared to be influenced by river discharge and wind-driven shelf circulation. The dispersion of higher POC concentrations offshore was impacted by the strength of the LC and LCEs that were seen in the SST and SSHA spatial patterns.

CEOF analysis between POC concentration and other physical factors(SST, SSHA, SSW, and PR) revealed that the non-seasonal component $(18$ and 30 months) accounted for a significant portion of the variance between parameters. For example, the first mode of POC and SST accounted for $48 \%$ of the total variance, and POC was inversely correlated with SST. This spatial pattern illustrated the east-west trend of POC concentration inshore and a limited dispersion of POC standing stock offshore. The first mode of POC and SSHA CEOF accounted for 35\% of the total variance, and $\mathrm{POC}$ concentration was inversely correlated with SSHA. This spatial pattern showed the relationship between POC variation and mesoscale circulation in the study area. Anticyclonic Loop Current and eddies appeared to cause lower POC concentrations, but cyclonic circulation appeared to enhance POC concentrations. The first mode of POC and SSW accounted for $37 \%$ of the total variance. This spatial pattern showed a positive relationship between POC concentration and wind, but these results explained little of the physical connection between POC concentration and wind, especially offshore. The first mode of POC and PR accounted for $42 \%$ of the total variance. Higher rainfall was related to larger POC concentrations in the northeastern Gulf coast.

Power spectra of eigenvectors from POC concentrations and other physical factors revealed periods of $15,18,22$, and 30 months. Positive values of eigenvectors occurred during 1997-1998 and 2003-2004, and negative values occurred during 1999-2001. These two periods(1997-1998 and 20032004) were ENSO events. During ENSO events, higher POC concentration was related to high runoff and high PM/nutrient water in the eastern Gulf of Mexico, but conditions were opposite in the western Gulf of Mexico. During 1999-2001, negative POC eigenvectors were related to normal or low river discharge, low PM/nutrient water in the eastern Gulf of Mexico. These inter-annual differences of POC concentrations over the study period were affected by one or more physical factors related to oceanatmospheric forcing.

\section{Acknowledgements}

The help of scientists and technicians who participated in the NEGOM cruises is greatly appreciated. This research work was supported by KORDI projects(KORDI contract numbers PM 55980). 


\section{References}

Berelson, W.M., 2001. The flux of particulate organic carbon into the ocean interior: a comparison of four U.S. JGOFS regional studies, Oceanography, 13(4): 59-67.

Brooks, D.A. and R.V. Legeckis, 1982. A ship and satellite view of hydrographic features in the western Gulf of Mexico, Journal of Geophysical Research, 87: 4195-4206.

Chung, S.P., W.D. Gardner, M.R. Landry, M.J. Richardson, and I.D. Walsh, 1998. Beam attenuation by microorganisms and detrital particles in the equatorial Pacific, Journal of Geophysical Research-Ocean, 103: 1266912681.

Deser, C. and M.L. Blackmon, 1993. Surface climate variations over the North Atlantic Ocean during winter: 1900-1989, Journal of Climate, 6: 1743-1753.

Emery, W.J. and R.E. Thomson, 1997. Data Analysis Methods in Physical Oceanography, Pergamon, Oxford, 643pp.

Frankignoul, C., F. Bonjean, and G. Reverdin, 1996. Interannual variability of surface currents in the tropical Pacific during 1987-1993, Journal of Geophysical Research, 101(C2): 36293647.

Frolov, S.A., G.G. Sutyrin, G.D. Rowe, and L.M. Rothstein, 2004. Loop Current eddy interaction with the western boundary in the Gulf of Mexico, Journal of Physical Oceanography, 34: 2223-2237.

Gardner, W.D., I.D. Walsh, and M.J. Richardson, 1993. Biophysical forcing of particle production and distribution during a spring bloom in the North Atlantic, Deep-Sea Research II, 40: 171-195.
Gardner, W.D., M.J. Richardson, and W.O. Smith, 2000. Seasonal patterns of water column particulate organic carbon and fluxes in the Ross Sea, Antarctica, Deep-Sea Research II, 47: 3423-3449.

Gardner, W.D., A.V. Mishonov, and MJ. Richardson, 2006. Global POC concentrations from in-situ and satellite data, Deep Sea Research II, 53: 718-740.

Gilbes, F., C. Thomas, JJ. Walsh, and F.E. MullerKarger, 1996. An episodic chlorophyll plume on the West Florida Shelf, Continental Shelf Research, 16: 1201-1224.

Hamilton, P., G.S. Fargion, and D.C. Biggs, 1999. Loop Current eddy paths in the western Gulf of Mexico, Journal of Physical Oceanography, 29: 1180-1207.

Hamilton, P., T.J. Berger, and W. Johnson, 2002. On the structure and motions of cyclones in the northern Gulf of Mexico, Journal of Geophysical Research-Oceans, 107: 3208-3226.

Hofmann, E.E. and S.J. Worley, 1986. An investigation of the circulation of the Gulf of Mexico, Journal of Geophysical ResearchOceans, 91: 14221-14236.

Kantha, L.H. and C.A. Clayson, 2000. Numerical Models of Ocean and Oceanic Processes. Academic Press, New York, 940pp.

Latif, M., and T.P. Barnett, 1994. Causes of decadal climate variability over the North Pacific and North America, Science, 206: 643-637.

McClain, C.R., G.C. Feldman, and S.B. Hooker, 2004. An overview of the SeaWiFS project and strategies for producing a climate research quality global ocean bio-optical time series, Deep Sea Research II, 51: 5-42.

Miller, A.J., D.R. Cayan, T.P. Barnett, N.E. Graham, and J.M. Oberhuber, 1994. Interdecadal variability of the Pacific Ocean: model 
response to observed heat flux and wind stress anomalies, Climate Dynamics, 9: 287-302.

Mishonov, A.V., W.D. Gardner, and MJ. Richardson, 2000. Prospects for using historical transmissometer data in large-scale assessment of POC, EOS, 80(49): 122.

Mishonov, A.V., W.D. Gardner, and M.J. Richardson, 2003. Remote sensing and surface POC concentration in the South Atlantic, Deep-Sea Research II, 50: 2997-3015.

Morey, S.L., P.J. Martin, J.J. O' Brien, A.A. Wallcraft, and J. Zavala-Hidalgo, 2003. Export pathways for river discharged fresh water in the northern Gulf of Mexico, Journal of Geophysical Research, 108(C10): 3303 (doi:10.1029/20002JC001674).

Paden, C.A., M.R. Abbott, and C.D. Winant, 1991. Tidal and atmospheric forcing of the upper ocean in the Gulf of California, 1: sea surface temperature variability, Journal of Geophysical Research-Ocean, 96(C10): 18337-18359.

Preisendorfer, R.W., 1988. Principal Component Analysis in Meteorology and Oceanography. Elsevier, Amsterdam, 452pp.

Rabalais, N.N., R.E. Tumer, D. Justic, Q. Dortch, W.J. Wiseman, and B.K. Sen Gupta, 1996. Nutrient Changes in the Mississippi River and system responses on the adjacent continental shelf, Estuaries, 19: 386-407.

Son, Y.B., 2006. POC algorithms based on spectral remote sensing data and its temporal and spatial variability in the Gulf of Mexico, Ph.D. thesis, 200 pp., Texas A\&M Univ., College Station.

Son, Y.B., W.D. Gardner, A.V. Mishonov, and M.J. Richardson, 2009a. Model-based remote sensing algorithms for particulate organic carbon(POC) in the Northeastern Gulf of Mexico, Journal of Earth System Science, 1:
1-10.

Son, Y.B., W.D. Gardner, A.V. Mishonov, and M.J. Richardson, 2009b. Multispectral remotesensing algorithms for particulate organic carbon(POC): The Gulf of Mexico, Remote Sensing of Environment, 113: 50-61.

Son, Y.B. and W.D. Gardner, 2010. Determining spatial and temporal variations of surface particulate organic carbon(POC) using in situ measurements and remote sensing data in the Northeastern Gulf of Mexico during El Niño and La Niña, "The Sea Journal of the Korean Society of Oceanography, 15(2): 51-61.

Stramski, D., R.A. Reynolds, M. Kahru, and B.G. Mitchell, 1999. Estimation of particulate organic carbon in the ocean from satellite remote sensing, Science, 285: 239-242.

Sturges, W. and R. Leben, 2000. Frequency of ring separation from the Loop Current in the Gulf of Mexico:A revised estimate, Journal of Physical Oceanography, 30: 1814-1819.

Thomas, A.C., D.W. Townsend, and R. Weatherbee, 2003. Satellite-measured phytoplankton variability in the Gulf of Maine, Continental Shelf Research, 23: 971-989.

Thurman, H.V. and A.P. Trujillo, 2002. Essentials of Oceanography, Prentice Hall, New Jersey, 524pp.

Walker, N.D., L.J. Rouse, B. Rouge, G.S. Fargion, and D.C. Biggs, 1994. The great flood of summer 1993: Mississippi River discharge studied, EOS, 75: 409-415.

Walker, N.D., 1996. Satellite assessment of Mississippi River plume variability: causes and predictability, Remote Sensing of Environment, 58: 21-35.

Wolter, K. and M.S. Timlin, 1998. Measuring the strength of ENSO - how does $1997 / 98$ rank? , Weather, 53: 315-324. 